\title{
1 An explanation for the isotopic offset between soil and stem water in a temperate tree species
} \\ Adrià Barbeta ${ }^{1,2 *}$, Teresa E. Gimeno ${ }^{1,3,4}$, Laura Clavé ${ }^{1}$, Bastien Fréjaville ${ }^{1}$, \\ Sam P. Jones ${ }^{1,5}$, Camille Delvigne ${ }^{1,6}$, Lisa Wingate ${ }^{1}$, Jérôme Ogée ${ }^{1}$ \\ ${ }^{1}$ INRAE, UMR1391 ISPA, 33140 Villenave d'Ornon, France \\ 2 BEECA, Universitat de Barcelona, 08028 Barcelona, Catalonia, Spain \\ ${ }^{3}$ Basque Centre for Climate Change, 48940 Leioa, Spain \\ ${ }^{4}$ IKERBASQUE, Basque Foundation for Science, 48008, Bilbao, Spain \\ ${ }^{5}$ Instituto Nacional de Pesquisas da Amazônia, Manaus CEP 69060-001, Brazil \\ ${ }^{6}$ Université catholique de Louvain, 1348 Louvain-la-Neuve, Belgium \\ * Correspondence to: Adrià Barbeta (adria.barbeta.margarit@gmail.com) and Jérôme Ogée \\ (jerome.ogee@inrae.fr)
}

- A growing number of field studies report isotopic offsets between stem water and its potential sources that prevent the unambiguous identification of plant water origin using water isotopes. We explored the causes of this isotopic offset by conducting a controlled experiment on the temperate tree species Fagus sylvatica.

- We measured $\delta^{2} \mathrm{H}$ and $\delta^{18} \mathrm{O}$ of soil and stem water from potted saplings growing on three soil substrates and subjected to two watering regimes.

- Regardless of substrate, soil and stem water $\delta^{2} \mathrm{H}$ were similar only near permanent wilting point. Under moister conditions, stem water $\delta^{2} \mathrm{H}$ was $11 \pm 3 \%$ more negative than soil water $\delta^{2} \mathrm{H}$, coherent with field studies. Under drier conditions, stem water $\delta^{2} \mathrm{H}$ became progressively more enriched than soil water $\delta^{2} \mathrm{H}$. Although stem water $\delta^{18} \mathrm{O}$ broadly reflected that of soil water, soil-stem $\delta^{2} \mathrm{H}$ and $\delta^{18} \mathrm{O}$ differences were correlated $(\mathrm{r}=0.76)$ and increased with transpiration rates indicated by proxies.

- Soil-stem isotopic offsets are more likely caused by water isotope heterogeneities within the soil pore and stem tissues, which would be masked under drier conditions due to evaporative 
29 enrichment, than by fractionation under root water uptake. Our results challenge our current 30 understanding of isotopic signals in the soil-plant continuum.

31 Keywords: ecohydrology, root water uptake, water isotopes, plant water sources, Fagus 32 sylvatica

33 Total word count: 6480

34 - Introduction: 2175

35 - Material and methods: 1670

36 - $\quad$ Results: 1025

37 - Discussion: 1602

$38 \quad-\quad$ Acknowledgements: 118

39 References: 60

40 Tables: 1.

41 Figures: 8 (Figs. from 1 to 8 in colour).

42 Supporting Information: 11 Figures and 1 Note.

43 


\section{Introduction}

45 Plant transpiration is the main flux returning water from the land surface to the atmosphere 46 (Jasechko et al., 2013) emphasising the importance of vegetation in the global water cycle. To 47 trace variations in land-atmosphere water fluxes it is necessary to identify the water pools accessed by plants and how these change over time and space. Analysis of the natural abundance of stable isotopes in water is a commonly used technique for this purpose (Dawson \& Ehleringer, 1991; Barbeta \& Peñuelas, 2017). This technique is usually applied under the assumption that no isotopic fractionation occurs during root water uptake, as suggested by a series of early observations conducted on plants grown hydroponically (Washburn \& Smith, 1934; Zimmermann et al., 1967). Although hydroponic systems do not have the mechanistic complexity and heterogeneity of natural systems (Penna et al., 2018), the evidence for root water uptake not fractionating paved the way for using water stable isotopes to infer plant water sources (White et al., 1985; Dawson \& Ehleringer, 1991), assess their spatiotemporal variability (Bertrand et al., 2014; Barbeta et al., 2015) and their ecological implications (Moreno-Gutiérrez et al., 2012; De Deurwaerder et al., 2018).

Improvements in the capability for higher throughput using modern water extraction and isotopic determination techniques have helped collect water isotopic datasets that are more comprehensive than ever before (Stumpp et al., 2018). Perhaps more importantly, plant water source studies are no longer restricted to either oxygen $\left(\delta^{18} \mathrm{O}\right)$ or hydrogen $\left(\delta^{2} \mathrm{H}\right)$ isotopic composition, but routinely present data for both isotopes. An emerging feature of studies using dual-isotope approaches is that oxygen and hydrogen isotopes do not always agree in the attribution of the source(s) of plant water. This is caused by isotopic offsets between stem water and all potential water sources, that is, the isotopic composition of stem water does not match any of the considered sources in the dual-isotope space. These isotopic offsets have been observed in field sites encompassing a wide range of soil types and biomes, including semi-arid shrublands (Wang et al., 2017), conifer forests (Geris et al., 2017 Brooks et al., 2010), broadleaved forests (Goldsmith et al., 2018; Barbeta et al., 2019 Bowling et al., 2017), urban gardens (Oerter and Bowen, 2017), tropical rainforests (Brum et al., 2018; De Deurwaerder et al., 2018)

72 and rice paddy fields (Mahindawansha et al., 2018). In such cases, the use of oxygen or

73 hydrogen isotopes separately can lead to significantly different attributions of plant water sources 
74 (Lin \& Sternberg, 1993; Evaristo et al., 2017; Brum et al., 2018; Barbeta et al., 2019). Some 75 authors acknowledged this caveat and used either $\delta^{2} \mathrm{H}$ or $\delta^{18} \mathrm{O}$ to infer plant water sources, or 76 proposed and discussed potential mechanisms and implications (Bowling et al., 2017; Evaristo et 77 al., 2017; Barbeta et al., 2019; Oerter \& Bowen, 2019; Oerter et al., 2019). However, in many 78 cases, soil-stem isotopic offsets are not addressed.

79 An isotopic offset between stem water and all potential water sources cannot be attributed solely 80 to methodological issues. For example, contamination of soil- or plant-extracted water by 81 organic compounds can bias measurements of the stable isotopes in water, especially when using 82 laser-based instruments (e.g. Schultz et al., 2011; Martín-Gómez et al., 2015; Millar et al., 83 2018). However, these contaminations are now routinely dealt with using custom, post84 measurement corrections and are unlikely to cause a systematic bias since (1) isotopic offsets 85 have been found in studies using both mass spectrometers (Brooks et al., 2010; Bowling et al., 86 2017; Brum et al., 2018; Goldsmith et al., 2018) and laser-based instruments (Geris et al., 2017; 87 Barbeta et al., 2019; De Deurwaerder et al., 2018) and (2) both types of analysers render similar 88 and reproducible results on the same soil water samples (Orlowski et al., 2018). Additional 89 confounding effects related to water extraction techniques should not be overlooked (Thorburn $e t$ 90 al., 1993; Walker et al., 1994; Millar et al., 2015; Orlowski et al., 2018). For example, cryogenic 91 vacuum extraction (CVE), is the most widely used technique nowadays but has been shown to 92 give results sensitive to many parameters such as soil texture, water content, extraction time or 93 temperature (Orlowski et al., 2018). Alternative soil and stem water extraction techniques exist 94 (Wassenaar et al., 2008; Munksgaard et al., 2014) and comparative studies often concluded that 95 contrasting results were caused by differences in extraction yields affecting the isotopic 96 composition of the extracted water of soil (Walker et al., 1994) and stem (Thorburn et al., 1993) 97 via Rayleigh distillation processes, or by large differences in organic contamination of the 98 extracted water (Millar et al., 2015). However, if well conducted, water extraction techniques 99 such as CVE lead to extraction yields $>99 \%$ and low levels of organic contamination (Orlowski 100 et al., 2013; Millar et al., 2015). Another possibility explaining soil-stem isotopic offsets is that 101 the pools of water extracted vary with different techniques, even though some of these pools 102 might be less relevant to the study of plant water sources (e.g. water adsorbed on soil particles or 103 plant storage water). For example, a recent study on wheat showed that the soil-stem isotopic 104 offset was reduced when using direct vapour equilibration on stems, compared to CVE (Millar et 
105 al., 2018). Unfortunately, for woody species, direct vapour equilibration presents additional 106 problems related to the interference of volatile organic compounds during isotopic determination 107 and still needs further development and testing (Volkmann et al. 2016; Raulerson, 2019).

108 Regardless of the technique, a consistent pattern is observed frequently across studies whereby 109 stem water generally plots below and to the right of any considered water source in the dual 110 isotope "space" (i.e., a graphical representation of $\delta^{2} \mathrm{H}$ vs. $\delta^{18} \mathrm{O}$ values) (Brooks et al., 2010).

111 Such a systematic pattern is unlikely to be attributed solely to soil and stem water extraction 112 artefacts but it remains to be tested whether it is reproducible under controlled conditions.

113 Isotopic offsets between source and stem water have now been reported in ecologically diverse 114 plant species, but was firstly observed in halophytic and xerophytic plants (Lin \& Sternberg, 115 1993; Ellsworth \& Williams, 2007). These drought and salinity tolerant plants have a highly 116 developed Casparian strip on the radial cell walls of the root endodermis that impedes apoplastic 117 movement of water, forcing water to move symplastically across cell membranes (Ellsworth \& 118 Williams, 2007 and references therein). Water movement through the symplastic route has been 119 hypothesized to fractionate hydrogen isotopes in water, leading to a 3-9\%o depletion of stem 120 water compared to soil water in halophytic and xerophytic plants (Lin \& Sternberg, 1993; 121 Ellsworth \& Williams, 2007). More recently, Poca et al., (2019) showed that arbuscular 122 mycorrhizal associations enhanced the isotopic offset between soil and stem water (up to -15\%) 123 in potted seedlings of the xerophytic species Acacia caven. They proposed that isotopic 124 fractionation occurred during trans-membrane water transport via aquaporins, and that this mode 125 of transport must be enhanced in presence of mycchorizal associations. However, the impairment 126 of the apoplastic pathway was not demonstrated in this study. More importantly, this mechanism 127 cannot explain why other studies, including our own results from a temperate deciduous forest 128 (Barbeta et al., 2019), found similar isotopic offsets (a soil water excess of 8.4\%o) in plant 129 species where root water uptake through the apoplastic route should not be impeded.

130 It is also increasingly recognised that soil water may exhibit pore-scale isotopic heterogeneity 131 created by water-surface interaction effects that leads to an isotopic depletion of adsorbed water 132 compared to bulk soil water (Oerter et al., 2014; Chen et al., 2016; Lin \& Horita, 2016; Lin et 133 al., 2018; Penna et al., 2018; Oerter \& Bowen, 2019). Then, a depletion of stem water compared 134 to bulk soil water could indicate that trees take up water adsorbed onto soil particles. However, 
135 we would expect roots to take up the most mobile (i.e. gravimetric and capillary) soil water (see 136 the discussion in Bowling et al., 2017) which, in contrast to adsorbed water, should be more 137 enriched than bulk soil water (Chen et al., 2016; Barbeta et al., 2019). Under low water 138 availability and high evaporative demand, it has also been shown that stem water loss via 139 evaporation can create significant isotopic enrichment of stem water (Bowling et al., 2017; 140 Martín-Gómez et al., 2017) further complicating the inference of plant water sources from stem 141 water's isotopic composition. Although such evaporative enrichment of stem water should be 142 easily detectable in the dual-isotope space and is a process that needs to be considered when 143 attempting to derive plant water sources, it cannot explain why stem water is more depleted in $144 \delta^{2} \mathrm{H}$ than any considered water source.

145 Isotopic heterogeneity in plant water pools was further proposed by Zhao et al. (2016) as an 146 alternative explanation for the observed soil-stem water isotopic offsets. They directly extracted 147 sap (i.e. vessel water) from stems of the desert riparian trees Populus euphratica and found that 148 its isotopic composition matched that of groundwater. On the other hand, total water from stem 149 or root samples was systematically depleted in ${ }^{2} \mathrm{H}$ with respect to sap water and all other likely 150 water sources. They attributed this observation to a putative discrimination during water 151 transport and redistribution within the plant. Unfortunately, repeating this experiment with other 152 species or during the dry season is very challenging, as it requires the xylem sap to be under 153 positive pressure to be collected. Only indirect evidence can be deducted, once all other 154 hypotheses have been discarded.

155 In this context, we conducted a glasshouse experiment with potted saplings of a temperate 156 deciduous tree (European beech, Fagus sylvatica L.) to quantify potential isotopic offsets 157 between plant and source water and to elucidate how these vary with water availability, soil 158 properties and plant physiological performance. We chose this temperate tree species because it 159 had been shown in a previous field study that isotopic separation between source and xylem 160 water was likely (Barbeta et al., 2019). In the field, the total extension of the root system is 161 difficult to assess so the presence of unconsidered water sources can never be completely ruled 162 out (Barbeta et al., 2019; Oerter \& Bowen, 2019). In contrast, the advantage of potted plants is 163 that the actual water source can be characterized more thoroughly. We thus wanted to verify that 164 the isotopic offsets observed in the field between xylem and soil water were reproducible under 
165 controlled conditions. Our experimental design builds up on the hypotheses formulated by 166 previous studies (Zhao et al., 2016; Martín-Gómez et al., 2017; Vargas et al., 2017; Barbeta et 167 al., 2019; Oerter \& Bowen, 2019) and more importantly, expands the range of soil water 168 availabilities tested to date. The isotopic offset between soil and stem water reported by Vargas 169 et al. (2017) was based on a glasshouse experiment with potted Persea americana saplings 170 subjected to a relatively mild water shortage (matching the study species demands) on two 171 contrasting soil types. Here we not only explored much harsher water shortages, but we also 172 complemented our experiment with a control treatment whereby plants were regularly watered 173 throughout the experiment to maintain the soil at field capacity. By doing so, we were revisiting 174 the early hydroponic experiments at the origin of the idea that root water uptake is a non175 fractionating process, while adding the complexity of textured soils. After several weeks of 176 regular irrigation to compensate for water losses, fractionation during root water uptake (noted $\varepsilon_{U}$ 177 in Fig. 1A) should lead to an isotopic enrichment of soil water above irrigation water $178\left(\delta_{\text {soil }}=\delta_{\mathrm{P}}+\varepsilon_{\mathrm{U}}\right)$ while stem water should arrive at isotopic steady state and reflect exactly the 179 isotopic composition of irrigation water $\left(\delta_{\text {soil }}=\delta_{\mathrm{P}}\right)$, leading to a constant isotopic offset between 180 bulk soil and stem waters (Fig 1A). If soil evaporation is not fully suppressed, soil water will 181 become slightly more enriched than $\delta_{\mathrm{P}}+\varepsilon_{\mathrm{U}}$ but the isotopic difference between soil and stem 182 water should not differ (see Notes S1). Pore-scale isotopic heterogeneity in soil and xylem water 183 pools may be an alternative explanation for the observed soil-xylem isotopic offsets (Fig. 1B). 184 Under well-watered conditions, the adsorbed soil water would represent a small fraction $\left(f_{a}\right)$ of 185 total soil water and thus the isotopic composition of bulk soil water $\left(\delta_{\text {soil }}\right)$ would resemble that of 186 irrigation water $\left(\delta_{\mathrm{P}}\right)$. In turn, the isotopic composition of bulk stem water $\left(\delta_{\text {stem }}\right)$ would still be 187 more depleted than $\delta_{\text {soil }}$ (and $\delta_{\mathrm{P}}$ ) because of isotopic heterogeneity within the stem (i.e. isotopic 188 differences between vessel/sap water and water in non-conductive tissues, Zhao et al., 2016). 189 This would imply that these non-conductive tissues are depleted compared to sap water, since 190 sap would have the signal of the water taken up $\left(\delta_{\mathrm{P}}\right)$ (Fig. 1B). To test further this alternative 191 situation, we also used three soil textures, including one containing rock fragments, to play on 192 the fraction of adsorbed water in soils and help disentangle the separate roles of soil water 193 content and water potential on the isotopic offsets. To sum up, our aim was to (i) test whether 194 isotopic offsets between stem water and their sources were reproducible in potted plants with a 
195 unique source of water and (ii) identify the soil physical and/or plant physiological mechanisms

196 producing these isotopic offsets.

\section{2. Material and Methods}

\subsection{Plant material and experimental design}

199 From February to July 2018 we grew saplings of $F$. sylvatica in a temperature-controlled 200 glasshouse (Talence, France). Climatic conditions inside the glasshouse were monitored with a 201 temperature and humidity probe (HMP60, Vaisala, Vanta, Finland) and a quantum sensor 202 (SQ200, Apogee, Logan, UT, US). Over the study period (14 May to 20 June 2018, $n=38$ days), 203 mean air temperature inside the glasshouse $( \pm \mathrm{SE})$ was $20 \pm 0.3{ }^{\circ} \mathrm{C}$ during the day and

$20416.3 \pm 0.2{ }^{\circ} \mathrm{C}$ at night. A shading cloth was permanently deployed from 24 April 2018 and mean 205 daily photosynthetic photon flux density (PPFD) was $10 \pm 0.9 \mathrm{~mol} \mathrm{~m}^{-2} \mathrm{~d}^{-1}$.

206 One-year old beech saplings (mean diameter of $2.1 \pm 0.5 \mathrm{~cm}$ ) were obtained from a commercial 207 nursery (Naudet pépinières, Leuglay, France) grown from seeds originating from the Armorican 208 massif (Bretagne, NE France). On 20 February 2018, we transplanted 220 plants into 3.5 L 209 squared pots filled with three soil types. The three soil types consisted of a volume mix of (1) 210 soil:sand:commercial substrate (2:1:1), (2) soil:sand:commercial substrate:crushed rocks 211 (10:5:5:1) and (3) soil:sand:commercial substrate:clay (10:2:5:3). Substrates were: sandy soil 212 from a nearby pine plantation (Jones et al., 2017) (Cestas, France), with a total organic C of $21333 \mathrm{~g} \mathrm{~kg}^{-1}$ and a total $\mathrm{N}<1 \mathrm{~g} \mathrm{~kg}^{-1}$; washed river sand (Gedimat, Levallois-Perret, France); 214 commercial peat substrate for plant growth (“Terrau Gazon”, Soufflet Vigne, Martillac, France); 215 crushed rocks obtained from oven-dried $\left(48 \mathrm{~h}\right.$ at $\left.105^{\circ} \mathrm{C}\right)$ limestone rocks collected near the 216 Ciron river (Pompéjac, France) and commercial soil conditioner (bentonite clay, Magellan-bio.fr, 217 Cysoing, France). According to texture analyses, the first and second (without the rocks) soil 218 types were classified as coarse sand and the third type was a sandy loam in the limit of sandy 219 clay loam, henceforth sandy clay loam. Soil water retention curves estimated from pedotransfer 220 functions (R package soilwater) are presented in Fig. S1. We transplanted 100 plants onto the 221 coarse sandy soil, 60 plants onto the coarse sandy soil with rocks and 60 plants onto the sandy 222 clay loam. 
223 From February 2018 until 13 May 2018 all pots were watered regularly to field capacity with tap 224 water $\left(\delta^{2} \mathrm{H}=-35.33 \pm 0.25\right.$ and $\left.\delta^{18} \mathrm{O}=-5.90 \pm 0.3\right)$ and soil water was allowed to freely 225 evaporate from the surface. Starting on 14 May 2018, we watered all pots daily to field capacity 226 for three consecutive days to ensure a homogeneous soil water pool in each pot. A set of 12 227 plants from each soil type continued to be watered to field capacity regularly (control treatment), 228 while watering was withheld for all other plants from the 17 May 2018 until the end of the 229 drying experiment on 20 June 2018 (drought treatment). A plastic top was placed on all pots to 230 reduce soil water evaporation on 17 May 2018. Mean soil gravimetric water content (GWC) over 231 time for each treatment and soil type was calculated from the weights of ten and five pots for the 232 drought and control treatments, respectively, for each soil type. Individual GWC and plant water 233 contents for sampled pots and plants were estimated from the soil and stem samples used for 234 cryogenic vacuum distillation. GWC was then converted to volumetric water content (VWC) 235 using the bulk density of each soil type. Based on the retention curve of each soil type, we 236 determined the VWC corresponding to the permanent wilting point (VWC at which soil matric 237 potential is $-1500 \mathrm{kPa}$ ). For each sampled pot, we calculated $\theta_{\text {rel }}$, the difference between the 238 VWC of a given pot minus the VWC at permanent wilting point. Thus, positives $\theta_{\text {rel }}$ values 239 corresponded to conditions in which soil water can be taken up by roots whilst negative values 240 imply that soil water is not extractable by the plant.

241 In addition to the two watering treatments, we applied a low vapour pressure deficit (VPD) 242 treatment during the first two sampling campaigns on a subset of plants from the drought 243 treatment with the rock-free coarse sandy soil. This treatment consisted of covering five plants 244 with a semi-transparent plastic bag the evening before the day of sampling. The aim was to 245 reduce transpiration for individual plants over the course of one day to assess its impact on 246 potential isotopic offsets between soil and stem water pools.

\subsection{Ecophysiological measurements and destructive harvests}

248 Over the course of the drying experiment, we performed five campaigns of ecophysiological 249 measurements and destructive harvests for water isotope analysis $(1,8,15,28$ and 35 days after 250 the last watering event of the drought treatment on 17 May 2018). On each campaign and each 251 soil type, we harvested three plants from the control and five from the drought treatment, except 252 on the first and second campaigns, where five additional plants from the low VPD treatment (on 
253 rock-free sandy soil) were also sampled. For each pot, a soil core from the surface to the bottom 254 of the pot was taken, homogenised in a clean plastic tray and sub-sampled for isotopic analysis. 255 For each plant we cut two 5cm-long lignified segments, one from the root and one from the stem 256 (separated by at least $2.5 \mathrm{~cm}$ below the aboveground stem) and peeled off the bark and phloem. 257 Soil, root and stem samples were rapidly transferred into screw-cap glass vials, sealed with 258 Parafilm ${ }^{\circledR}$ and stored in a cool box until transported to the laboratory where they were stored at $259 \quad 4^{\circ} \mathrm{C}$ until further analysis.

260 The day of each destructive harvest (conducted in early afternoon), ecophysiological 261 measurements were also performed on leaves from the harvested plants and included 262 measurements of stomatal conductance to water vapour $\left(g_{\mathrm{s}}\right)$ and leaf water potential at predawn $263\left(\Psi_{\mathrm{pd}}\right)$ and midday $\left(\Psi_{\mathrm{md}}\right)$. Leaf water potential was measured with a custom-made Scholander 264 type chamber (DG Meca, Gradignan, France) on one leaf per plant. Stomatal conductance was 265 measured at mid-morning (10:30-11:30, local time) with two cross-calibrated handheld 266 porometers (SC-1 Leaf Porometer, Decagon Inc., Pullman, WA, US) on one leaf per plant. On 267 the second campaign, we measured $g_{\mathrm{s}}$ with the two handheld porometers and with an infrared gas 268 analyser (IRGA, LI-COR 6400, LI-COR, Lincoln, NE, US), on the same leaves and matching the 269 conditions inside the gas exchange chamber (temperature, humidity, PPFD and $\mathrm{CO}_{2}$ 270 concentration) to those prevailing in the glasshouse. The significant correlation between $g_{\mathrm{s}}$ 271 measurements showed that measurements from the handheld porometers neither overestimated 272 nor underestimated stomatal conductance compared to the IRGA $\left(p=0.001, R^{2}=0.45\right.$, slope: $2731.03 \pm 0.25)$.

\section{$274 \quad 2.3$ Cryogenic water extraction and analyses of water isotopic composition}

275 The extraction of water from soil, stem, root and rock samples was performed by cryogenic 276 vacuum distillation using a design and methodology proposed by Orlowski et al. (2013), as 277 described in Jones et al. (2017). At the onset of the extraction, up to 24 samples kept in sampling 278 glass vials were inserted in larger extraction glass vials connected to a vacuum extraction line 279 and frozen in liquid nitrogen. The extraction line was then evacuated down to an atmospheric 280 (static) pressure of less than $1 \mathrm{~Pa}$ and composed of 24 glass U-shape tubes that were then 281 inserted in liquid nitrogen to create a cold trap. Samples were then immersed in a water bath at 282 ambient temperature, and the water bath was gradually heated up to $80^{\circ} \mathrm{C}$ (within $1 \mathrm{~h}$ ) to start the 
283 distillation process. Samples remained in the heated bath at $80^{\circ} \mathrm{C}$ for $2.5 \mathrm{~h}$. Pressure in the

284 extraction line was continuously monitored with sub-atmospheric pressure sensors (APG100 285 Active Pirani Vacuum Gauges, Edwards, Burgess Hill, UK) to check that the lines remained 286 leak-tight throughout the entire extraction and that the water extraction had ended. Samples were 287 weighed before and after the extraction and before and after being oven-dried for $24 \mathrm{~h}$ at $105^{\circ} \mathrm{C}$ to 288 assess extraction efficiency. GWC was estimated from each sample by using the weight 289 measured before and after the cryogenic extraction and again after oven-drying (Newberry et al., 290 2017).

291 The isotopic composition $\left(\delta^{2} \mathrm{H}\right.$ and $\left.\delta^{18} \mathrm{O}\right)$ of the extracted waters was measured with an off-axis 292 integrated cavity optical spectrometer (TIWA-45EP, Los Gatos Research, USA) coupled to a 293 liquid auto-sampler and vaporiser (LC-xt, PAL systems, Switzerland). All isotopic data reported 294 here are calibrated using two internal standards and expressed on the VSMOW-SLAP scale, as 295 described in Jones et al. (2017). Because the presence of organic compounds (ethanol, methanol 296 and/or other biogenic volatile compounds) in water samples can lead to large isotopic 297 discrepancies in laser-based analyses (Martín-Gómez et al., 2015; Wassenaar et al. 2018), we 298 developed a post-correction algorithm for the presence of organic compounds based on the 299 narrowband (for methanol) and broadband (for ethanol) metrics of the absorption spectra (Brian 300 Leen et al., 2012). Post-corrections relating how these metrics affect the isotopic composition of 301 waters contaminated with known amounts of ethanol and methanol were developed specifically 302 for our instrument. Overall, these post-corrections were usually higher for stem water than for 303 meteoric or soil water samples but always remained quite small (i.e. below $1.5 \%$ for $\delta^{2} \mathrm{H}$ and 304 below $0.7 \%$ for $\left.\delta^{18} \mathrm{O}\right)$.

\section{$305 \quad 2.4$ Data analyses}

306 Statistical analysis was conducted in R (R Core Team, 2019) using either general linear models 307 (GLM) or generalized linear mixed models (GLMM, for those cases where we set some of the 308 factors as random) from the $R$ package lme4 (Bates et al., 2015). The effect of soil type and 309 drought treatment over the course of the experiment on GWC, plant water potentials at predawn $310\left(\Psi_{\mathrm{pd}}\right)$, midday $\left(\Psi_{\mathrm{md}}\right)$, the difference between them $(\Delta \Psi)$ and the isotopic composition of the 311 different water pools (soils, stems, roots and rocks) was tested with GLMs with interactions 312 between all factors. In order to determine the most relevant factors explaining the variability in 
313 isotopic offsets $\left(\Delta^{18} \mathrm{O}\right.$ and $\Delta^{2} \mathrm{H}$, calculated as the difference between plant and soil water isotopic 314 composition), we conducted a stepwise regression model. In the saturated model, we considered, $315 \theta_{\text {rel }}$, soil type, $g_{s}, \Psi_{\mathrm{pd}}$ and $\Psi_{\mathrm{md}}$. Based on the Akaike Information Criterion (AIC) (Akaike, 1974), 316 we progressively removed those variables that were not significant, deciding to maintain this 317 removal if the AIC decreased (better compromise between goodness of fit and model simplicity).

\section{3. Results}

\subsection{Manipulation effects on soil water content and plant water use}

320 Soil gravimetric water content $(\mathrm{GWC})$ decreased over time $(P<0.001)$ in the drought treatment, 321 while it was maintained in the control treatment (Fig. 2). Soil type had a significant effect on the 322 drying rate $(P=0.001$ for the soil type $\times$ time $\times$ treatment interaction), with fastest drying rates 323 in the rocky sandy soil and slowest drying rates in the sandy clay loam (Fig. S2).

324 Predawn leaf water potential $\left(\Psi_{\text {pd }}\right)$ also decreased over time in the drought treatment while it was 325 maintained in control pots $(P<0.001$, for the treatment effect, Fig. 2$)$. The impact of the drought 326 treatments on GWC was observed rapidly in the different soils, but differences in $\Psi_{\text {pd }}(P>0.15$ 327 for soil type and its interactions) started to decline only 20 days after the last watering event 328 (Fig. S2). Similarly, plants in the drought treatment had more negative $\Psi_{\mathrm{md}}$ and smaller $\Delta \Psi$ than 329 plants in the control treatment $\left(P=0.04\right.$ and 0.001 , for $\Psi_{\mathrm{md}}$ and $\Delta \Psi$, respectively), but with no 330 significant difference between soil types (Fig. S3). Plants in the control treatment had higher $g_{\mathrm{s}}$ 331 than plants in the drought treatment $(P<0.001)$ (Fig. 2$)$ and did not show any difference in

332 stomatal conductance $\left(g_{\mathrm{s}}\right)$ between soil types (not shown). The deliberate reduction in VPD 333 promoted by bagging the plants overnight prior to the first two sampling dates successfully 334 increased $g_{s}$, but did not affect predawn water potentials (not shown).

335 Plant water content was not sensitive to the drought treatment. Both control and drought plants 336 showed a progressive decrease in root and stem water content (relative to total weight) over the 337 experiment, with no significant difference between treatments (Fig. 2). Roots always had 338 significantly higher water content than stems. Overall, the drought treatment had a significant 339 influence on the plant water status only for the last two sampling campaigns (i.e. when predawn 340 water potential fell below -1MPa), coinciding with significantly lower leaf stomatal conductance 
341 and predawn water potential despite similar root and stem water contents, compared to the 342 control plants.

\section{3.2 Manipulation effects on the isotopic composition of water pools}

344 The isotopic composition of soil water was always equal to or more enriched (i.e. had higher $345 \delta^{18} \mathrm{O}$ and $\delta^{2} \mathrm{H}$ ) than irrigation water, even in the (regularly irrigated) control treatment (Figs. 3 346 and 4). This isotopic enrichment above irrigation water of soil water in the control treatment was stronger when the time between the last irrigation and the date of sampling was longer, and comparable to the enrichment in the drought treatment during the first three campaigns. In the drought treatment, and despite our attempt to prevent soil evaporation, the $\delta^{18} \mathrm{O}$ of soil water increased over time, especially over the last two sampling campaigns (Fig. 3). In contrast, soil water $\delta^{2} \mathrm{H}$ did not follow a progressive enrichment as the soil dried, as it is expected from soil evaporative enrichment theory (Barnes \& Allison, 1983). These patterns were visible and reproducible amongst all soil types (Fig. S4).

354 Root and stem water $\delta^{18} \mathrm{O}$ broadly reflected the $\delta^{18} \mathrm{O}$ of the corresponding soil water (Fig. 3). In 355 contrast, root and stem water $\delta^{2} \mathrm{H}$ from the control treatment was always more depleted than soil 356 water $\delta^{2} \mathrm{H}(P<0.001$ and $P<0.01$, Fig. 3). A similar pattern was also visible in the drought 357 treatment for the first three sampling campaigns (i.e. until the drought treatment had a significant 358 influence on the plant water status, see section 3.1). However, for the last two campaigns, root and stem water $\delta^{2} \mathrm{H}$ started to increase and became more enriched than soil water $\delta^{2} \mathrm{H}$ (Fig. 3). No significant difference was found between root and stem water $\delta^{2} \mathrm{H}$.

361 Differences in the isotopic compositions of stem, root and soil water described above were not 362 affected by soil type (Fig. S4). However, water extracted from limestone rocks was more 363 enriched than soil water in response to drought in both $\delta^{18} \mathrm{O}(P<0.05)$ and $\delta^{2} \mathrm{H}(P<0.001)$ but 364 this did not affect the isotopic composition of plant and soil water pools (Fig. S4).

\subsection{Isotopic offsets between plant and soil water pools}

366 Although soil, root and stem water $\delta^{18} \mathrm{O}$ and $\delta^{2} \mathrm{H}$ behaved differently upon drying, a strong 367 correlation between $\delta^{18} \mathrm{O}$ and $\delta^{2} \mathrm{H}$ soil-plant offsets $\left(\Delta^{18} \mathrm{O}\right.$ and $\left.\Delta^{2} \mathrm{H}\right)$, for both roots and stems was 368 observed (Fig. 5). The slope of the orthogonal distance linear regression (that accounts for errors 
on both axes) between $\Delta^{18} \mathrm{O}$ and $\Delta^{2} \mathrm{H}$ was $7.9 \pm 0.7$ and $7.2 \pm 0.8$ for soil-stem and soil-root 370 offsets, respectively.

371 The $\delta^{2} \mathrm{H}$ soil-stem water offset $\left(\Delta^{2} \mathrm{H}\right)$ was significantly different from zero $(P<0.001)$ for 372 control plants, with a mean value of $10.6 \pm 3.05 \%$, indicating that stem water was significantly 373 more depleted than soil water (Figs. S5). In the drought treatment, $\Delta^{2} \mathrm{H}$ shifted from positive to 374 negative values over time $(P<0.001$, Fig. S5), indicating that stem water became significantly 375 more enriched in ${ }^{2} \mathrm{H}$ than the corresponding soil water. This shift occurred only when soil water 376 content was below the permanent wilting point (Fig. S5), and when the drought treatment started 377 to have significant effects on leaf stomatal conductance and predawn water potential (Fig. 2). 378 The $\delta^{18} \mathrm{O}$ soil-stem water offset $\left(\Delta^{18} \mathrm{O}\right)$ was not significantly different from zero in both 379 treatments (Fig. S5a,c), although $\Delta^{18} \mathrm{O}$ co-varied with $\Delta^{2} \mathrm{H}$ (Fig. 4). Therefore, stem $\delta^{18} \mathrm{O}$ 380 reflected soil water $\delta^{18} \mathrm{O}$. Because root and stem water did not differ significantly in their 381 isotopic composition, soil-root isotopic offsets followed similar patterns as soil-stem $\Delta^{2} \mathrm{H}$ 382 and $\Delta^{18} \mathrm{O}$ (Fig. S5b,d). The effect of $\theta_{\text {rel }}$ was significant and negative for $\Delta^{18} \mathrm{O}$, but negligible for $383 \Delta^{2} \mathrm{H}$ (Fig. 6). For both $\Delta^{18} \mathrm{O}$ and $\Delta^{2} \mathrm{H}$, we found positive effects of $\Psi_{\mathrm{md}}$ and $\Delta \Psi$ (Table 1). Leaf $384 \Delta \Psi$ was the variable that explained the largest part of the variance in $\Delta^{18} \mathrm{O}$ and $\Delta^{2} \mathrm{H}$. The larger 385 the leaf $\Delta \Psi$, the larger the soil-stem isotopic offsets (Fig. 7 and Table 1). Finally, pots exposed to 386 a low VPD treatment had significantly lower soil-stem $\Delta^{2} \mathrm{H}$ than ambient VPD plants $(P<0.05)$, 387 but not significantly different $\Delta^{18} \mathrm{O}$ (Fig. S6). Plant water content, either in roots or stems, did 388 not explain the isotopic differences between treatments.

\section{4. Discussion}

390 Our results from a controlled experiment with potted $F$. sylvatica saplings revealed that hydrogen 391 isotope offsets between soil and plant water pools $\left(\Delta^{2} \mathrm{H}\right)$ are consistent over a range of soil types 392 but highly dependent on plant water status. As long as soil water remained above the permanent 393 wilting point, stem and root water were significantly more depleted in ${ }^{2} \mathrm{H}$ than their 394 corresponding source water (Figs. 3 and S5), leading to a soil-stem isotopic offset in $\Delta^{2} \mathrm{H}$ of a 395 similar magnitude to those observed in the field for adult $F$. sylvatica and Quercus robur trees 396 (Goldsmith et al., 2018; Barbeta et al., 2019) and a number of other species (Lin \& Sternberg, 397 1993; Ellsworth \& Williams, 2007; Brooks et al., 2010; Zhao et al., 2016; Evaristo et al., 2017; 398 Brum et al., 2018; Oerter \& Bowen, 2019). The reproducibility of this offset in potted and 
irrigated F. sylvatica saplings demonstrates that soil-plant isotopic offset is not restricted to

400 halophytes (Lin \& Sternberg, 1993; Ellsworth \& Williams, 2007; Eley et al., 2014; Redelstein et

401 al., 2018) or xerophytes (Ellsworth \& Williams, 2007; Zhao et al., 2016) but is more general and

402 can occur as well in temperate forests. It further suggests that, in the field, soil-plant $\delta^{2} \mathrm{H}$ offsets

403 cannot be solely attributed to a missing water source (Oerter \& Bowen, 2019; Oerter et al.,

404 2019). Our results that the isotope offset can be cancelled or even reversed when predawn water

405 potential drops below - $1 \mathrm{MPa}$ in F. sylvatica may also explain why some field studies do not

406 observe such an offset, especially in semi-arid sites (e.g. Grossiord et al., 2016) or in temperate

407 sites during the dry season (e.g. Bariac et al., 1990). The long-standing principle that there is no

408 isotopic fractionation within soil and stem water pools requires reconsideration, at least for $\delta^{2} \mathrm{H}$.

409 Meanwhile, oxygen isotope offsets $\left(\Delta^{18} \mathrm{O}\right)$ between soil and plant water were also present and

410 proportional to $\Delta^{2} \mathrm{H}$ (Fig. 5), although not always significant (Fig. S5).

411 Vargas et al. (2017) performed a similar experiment on potted Persea americana plants and 412 found soil-stem isotopic offsets that were comparable to those reported here. Their soil-stem $\Delta^{2} \mathrm{H}$ 413 and $\Delta^{18} \mathrm{O}$ showed a linear relationship with a slope of $10.6 \pm 3.8$, i.e., in the same range as the

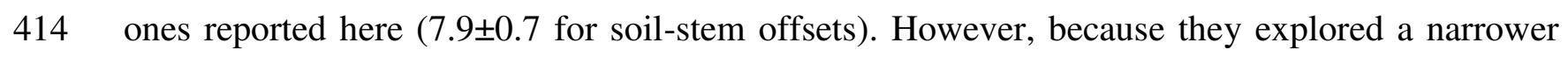
415 range of soil water availability, they did not detect the sign inversion in both $\Delta^{18} \mathrm{O}$ and $\Delta^{2} \mathrm{H}$ as 416 found here when $\Psi_{\text {pd }}$ fell below -1 MPa (Fig. S5). Vargas et al. (2017) explained the observed 417 soil-stem isotopic offset by a putative isotope fractionation process during root water uptake (see 418 Introduction). However, our results from the control treatment do not support this hypothesis, as 419 theoretically, this would result in an enrichment of soil water whilst stem water would reflect 420 irrigation water (Fig. 1A, see the theoretical framework in Supplementary Information). In 421 contrast, we found a strong depletion of stem water $\delta^{2} \mathrm{H}$ compared to irrigation water in the 422 control treatments that cannot be explained by root discrimination and/or soil evaporation (see 423 Supplementary Information). A more likely explanation for the isotopic depletion of bulk stem 424 water compared to soil water in our experiment (and that of Vargas et al.) is that storage water in 425 the xylem tissue is depleted compared to vessel water (i.e. sap) (Fig. 1B).

426 Such isotopic offsets between bulk stem water and vessel (sap) water have been reported in 427 woody plants (Zhao et al., 2016). In addition, large isotopic differences between leaf water pools 428 from the multiple epidermis (storage tissues) (White et al., 1985) and the spongy parenchyma 
429 (photosynthetic tissues) of the CAM plant Peperomia congesta (HBK) have also been 430 documented (Yakir et al., 1994). The isotopic difference between storage and photosynthetic 431 tissues was comparable to the isotopic offsets reported here between soil and stem water (i.e. $432>10 \%$ ). Interestingly this isotopic difference was maintained only under turgid conditions and 433 vanished under water limitations (Yakir et al., 1994). This is coherent with our findings that the 434 isotopic offsets between soil and stem water vanishes around the permanent wilting point 435 (Fig. 6). However this would imply that, under low transpiration, the mixing of the storage and 436 vessel water in the stem becomes more pronounced, resulting in a lower fractionation between 437 the two water pools ( $\varepsilon_{\mathrm{x}}$ in Fig. 1B). Such a reduction of $\varepsilon_{\mathrm{x}}$ under water limitations would need to 438 be tested using techniques that allow isotopic determination of vessel and stem tissue water 439 separately. However, a reduction of $\varepsilon_{\mathrm{x}}$ cannot explain why stem water becomes more enriched 440 than soil water below the permanent wilting point (Fig. 6). A plausible explanation for this 441 pattern is that, when water is limited, stem evaporation $\left(E_{x}\right)$ enriches stem water above the values 442 of soil water, because the transpiration stream cannot replenish the stem tissue at a fast enough 443 rate (Martin-Gomez et al., 2017).

444 It remains to be explained why, in the drought treatment, soil water $\delta^{18} \mathrm{O}$ increases continuously 445 while its $\delta^{2} \mathrm{H}$ counterpart remains constant or even decreases once permanent wilting point is 446 reached (Fig. 3). A very similar pattern had already been observed on wheat and sunflower, and 447 had been interpreted as a possible effect of plant organic matter decomposition (Allison et al., 448 1984). Vargas et al. (2017) rejected this idea on the basis that, in their experiment, potted cut 449 stems (that had decaying roots and no transpiring canopy) did not produce any depletion in soil 450 water $\delta^{2} \mathrm{H}$. However, soil water in pots with live plants was not depleted either in their 451 experiment and, as mentioned above, they did not explore the full range of water potentials that 452 were explored in this study or in Allison et al. (1983). Our data demonstrated that only once 453 permanent wilting point had been reached and predawn water potential dropped below -1 MPa, 454 did soil water $\delta^{18} \mathrm{O}$ and $\delta^{2} \mathrm{H}$ start to exhibit clear opposite trends. Thus, we hypothesise that 455 Vargas et al. did not observe the same trends as here because the drought treatment they applied 456 was too mild. In addition, we propose an alternative explanation to that of Allison et al. (1983) 457 and suggest that this pattern in soil water isotopes under dry conditions results from surface 458 isotope effects. Indeed, as soil dries adsorbed water becomes an increasingly larger fraction $\left(\mathrm{f}_{\mathrm{a}}\right)$ 459 of total soil water (Tuller \& Or, 2005; Chen et al., 2016; Lu, 2016). In the two last sampling 


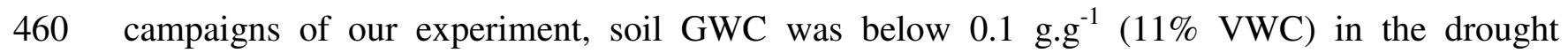
461 treatment (Fig. 2). According to Lu (2016), adsorbed water can range from 1.7\% VWC in sandy 462 soils to $12.8 \% \mathrm{VWC}$ in silty clay soils. It is thus reasonable to assume that the isotopic 463 fractionation associated with adsorbed water can dominate the isotopic composition of dry soils. 464 Meanwhile, under sustained drought, the remaining bulk soil water would still become progressively enriched because of soil evaporation $\left(E_{\mathrm{s}}\right)$. Depending on the balance between the enrichment caused by evaporation and the depletion caused by the higher fraction of adsorbed water, the isotopic composition of bulk soil water could show different trends during drying periods, either positive or negative. Because soil evaporative enrichment creates a relatively stronger enrichment in ${ }^{18} \mathrm{O}$ than in ${ }^{2} \mathrm{H}$ (i.e. the slope of the evaporation line in the dual isotope space is lower than the slope of the meteoric water line) and surface isotope effects are much stronger for ${ }^{2} \mathrm{H}$ than for ${ }^{18} \mathrm{O}$ (Chen et al., 2016; Lin et al., 2018), it is plausible that soil water $\delta^{18} \mathrm{O}$ enriches while soil water $\delta^{2} \mathrm{H}$ becomes depleted, at least when the soil water balance is dominated by root water uptake. In the field, this opposing trend between soil water $\delta^{18} \mathrm{O}$ and $474 \delta^{2} \mathrm{H}$ may be harder to observe as capillary rise may compensate water losses, minimising the influence of adsorbed water, and the depletion of soil water above the evaporation front may be dominated by the back diffusion of (depleted) atmospheric vapour into the soil (Barnes \& Allison, 1983).

In conclusion, we propose the following explanation for the dynamics of soil-plant isotopic offsets reported here and in other studies. This is the most plausible explanation, but it is still untested in a qualitative sense. Plants take up mobile and capillary soil water during transpiration. In wet conditions (control treatment), this soil water pool constitutes a large 482 fraction of bulk soil water with an isotopic composition $\left(\delta_{\mathrm{m}}\right)$ close to that of irrigation water. 483 However, bulk stem water is depleted compared to mobile and capillary soil water (Zhao et al., 2016) because it comprises a mix of vessel water that reflects mobile/capillary soil water, with storage water that is depleted compared to vessel water (Fig. 8A). The origin of this depletion of storage water in the stem is unknown, but could be related to surface processes on plant organic surfaces (Chen et al., 2016). In contrast, during dry conditions (drought treatment), adsorbed water represents an increasingly larger fraction of bulk soil water, creating a significant depletion of bulk soil water compared to mobile/capillary water, and thus compared to vessel water in a transpiring plant. Bulk stem water remains depleted compared to vessel water but, as plant 
491 transpiration becomes strongly reduced under prolonged drought, stem evaporation $\left(\mathrm{E}_{\mathrm{x}}\right)$

492 increasingly enriches bulk stem water above the composition of soil mobile/capillary water $\left(\delta_{\mathrm{m}}\right)$

493 (Fig. 8B). Our findings that the isotopic offsets between soil and stem water increase with plant

494 transpiration proxies such as the diurnal amplitude of stem water potential $\Delta \Psi$ (Fig. 7) or

495 stomatal conductance (Fig. S7) indicate that soil-stem isotopic offsets also reflect the

496 competition between transpiration and stem evaporation (Martín-Gómez et al., 2017) and the

497 matric potential of soil and plant water pools (Gaj \& McDonnell, 2019).

499 Acknowledgements

500 Many thanks to Steven Wohl, Nicolas Devert, Céline Gire, Lionel Jordan-Meille and the staff at

501 Bordeaux Science Agro for technical support, as well as Nicolas Cornette, Yann Cochet and

502 Kenza Bakouri for assistance in the glasshouse. This study received funding from the

503 EC2CO/BIOHEFECT program (CNRS, France), the French national research agency (projects

504 Hydrobeech, Climbeech and Micromic within the Cluster of Excellence COTE with grant 505 agreement ANR-10-LABX-45; project ORCA with grant agreement ANR-13-BS06-0005-01), 506 the European Research Council (ERC) under the EU Seventh Framework Program (FP7/2007507 2013, with grant agreement no. 338264, awarded to L.W) and the Aquitaine Region (project 508 Athene with grant agreement 2016-1R20301-00007218). A.B. also acknowledges an IdEx 509 Bordeaux postdoctoral fellowship from the Université de Bordeaux (contract no. 22001162).

510 Author contributions

511 A.B., T.E.G. and J.O. designed the study; T.E.G., L.C., A.B. and C.D. grew plants, applied 512 irrigation treatments and measured soil and plant parameters; A.B., B.F., S.P.J. and J.O. 513 performed stable isotope analyses; A.B. and J.O wrote the manuscript with contributions from all 514 authors. 
517 Akaike H. 1974. A New Look at the Statistical Model Identification. IEEE Transactions on 518 Automatic Control 19: 716-723.

519 Allison GB, Barnes CJ, Hugues MW, Leaney FWJ. 1984. Effect of Climate and Vegetation 520 on Oxygen-18 and Deuterium Profiles in Soils. Isotope hydrology, 1983 : proceedings of an 521 International Symposium on Isotope Hydrology in Water Resources Development: 105-123.

522 Barbeta A, Jones SP, Clavé L, Wingate L, Gimeno TE, Fréjaville B, Wohl S, Ogée J. 2019. 523 Unexplained hydrogen isotope offsets complicate the identification and quantification of tree 524 water sources in a riparian forest. Hydrology and Earth System Sciences 23: 1-31.

525 Barbeta A, Mejía-Chang M, Ogaya R, Voltas J, Dawson TE, Peñuelas J. 2015. The 526 combined effects of a long-term experimental drought and an extreme drought on the use of 527 plant-water sources in a Mediterranean forest. Global Change Biology 21: 1213-1225.

528 Barbeta A, Peñuelas J. 2017. Relative contribution of groundwater to plant transpiration 529 estimated with stable isotopes. Scientific Reports 7: 1-10.

530 Bariac T, Jusserand C, Mariotti A. 1990. Evolution de la composition isotopique de l'eau 531 (180) dans le continuum sol-plante-atmosphere. Catena 54: 413-424.

532 Barnes CJ, Allison GB. 1983. The distribution of deuterium and 180 in dry soils. Journal of 533 Hydrology 60: 141-156.

534 Bates D, Mächler M, Bolker B, Walker S. 2015. Fitting Linear Mixed-Effects Models using 535 lme4. Journal of Statistical Software 67.

536 Bertrand G, Masini J, Goldscheider N, Meeks J, Lavastre V, Celle-Jeanton H, Gobat JM, 537 Hunkeler D. 2014. Determination of spatiotemporal variability of tree water uptake using stable 538 isotopes $(\delta 18 \mathrm{O}, \delta 2 \mathrm{H})$ in an alluvial system supplied by a high-altitude watershed, Pfyn forest, 539 Switzerland. Ecohydrology 7: 319-333.

540 Bowling DR, Schulze ES, Hall SJ. 2017. Revisiting streamside trees that do not use stream 541 water: can the two water worlds hypothesis and snowpack isotopic effects explain a missing 542 water source? Ecohydrology 10: 1-12. 
543 Brian Leen J, Berman ESF, Liebson L, Gupta M. 2012. Spectral contaminant identifier for 544 off-axis integrated cavity output spectroscopy measurements of liquid water isotopes. Review of 545 Scientific Instruments 83.

546 Brooks JR, Barnard HR, Coulombe R, McDonnell JJ, Renée Brooks J, Barnard HR, 547 Coulombe R, McDonnell JJ. 2010. Ecohydrologic separation of water between trees and 548 streams in a Mediterranean climate. Nature Geoscience 3: 100-104.

549 Brum M, Vadeboncoeur MA, Ivanov V, Asbjornsen H, Saleska S, Alves LF, Penha D, Dias 550 JD, Aragão LEOC, Barros F, et al. 2018. Hydrological niche segregation defines forest 551 structure and drought tolerance strategies in a seasonal Amazon forest. Journal of Ecology: 318552333.

553 Chen G, Auerswald K, Schnyder H. 2016. $2 \mathrm{H}$ and $18 \mathrm{O}$ depletion of water close to organic 554 surfaces. Biogeosciences 13: 3175-3186.

555 Dawson TE, Ehleringer JR. 1991. Streamside trees that do not use stream water. Nature 350: $556335-337$.

557 De Deurwaerder H, Hervé-Fernández P, Stahl C, Burban B, Petronelli P, Hoffman B, 558 Bonal D, Boeckx P, Verbeeck H. 2018. Liana and tree below-ground water competition559 evidence for water resource partitioning during the dry season. Tree Physiology: 1-13.

560 Eley Y, Dawson L, Black S, Andrews J, Pedentchouk N. 2014. Understanding 2 H / 1 H 561 systematics of leaf wax $\mathrm{n}$-alkanes in coastal plants at Stiffkey saltmarsh, Norfolk, UK. 562 Geochimica et Cosmochimica Acta 128: 13-28.

563 Ellsworth PZ, Williams DG. 2007. Hydrogen isotope fractionation during water uptake by 564 woody xerophytes. Plant and Soil 291: 93-107.

565 Evaristo J, McDonnell JJ, Clemens J. 2017. Plant source water apportionment using stable 566 isotopes: A comparison of simple linear, two-compartment mixing model approaches. 567 Hydrological Processes 31: 3750-3758.

568 Gaj M, McDonnell JJ. 2019. Possible soil tension controls on the isotopic equilibrium 569 fractionation factor for evaporation from soil. Hydrological Processes 33: 1629-1634. 
570 Geris J, Tetzlaff D, McDonnell JJ, Soulsby C. 2017. Spatial and temporal patterns of soil 571 water storage and vegetation water use in humid northern catchments. Science of the Total 572 Environment 595: 486-493.

573 Goldsmith GR, Allen ST, Braun S, Engbersen N, Romero González-Quijano C, Kirchner 574 JW, Siegwolf RTW. 2018. Spatial variation in throughfall, soil, and plant water isotopes in a 575 temperate forest. Ecohydrology: e2059.

576 Jasechko S, Sharp ZD, Gibson JJ, Birks SJ, Yi Y, Fawcett PJ. 2013. Terrestrial water fluxes 577 dominated by transpiration. Nature 496: 347-350.

578 Jones SP, Ogée J, Sauze J, Wohl S, Saavedra N, Fernández-Prado N, Maire J, Launois T, 579 Bosc A, Wingate L. 2017. Non-destructive estimates of soil carbonic anhydrase activity and 580 associated soil water oxygen isotope composition. Hydrology and Earth System Sciences 21: $581 \quad 6363-6377$.

582 Lin Y, Horita J. 2016. An experimental study on isotope fractionation in a mesoporous silica583 water system with implications for vadose-zone hydrology. Geochimica et Cosmochimica Acta 584 184: $257-271$.

585 Lin Y, Horita J, Abe O. 2018. Adsorption isotope effects of water on mesoporous silica and 586 alumina with implications for the land-vegetation-atmosphere system. Geochimica et 587 Cosmochimica Acta 223: 520-536.

588 Lin G, Sternberg L da SL. 1993. Hydrogen isotopic fractionation by plant roots during water 589 uptake in coastal wetland plants. In: Ehleringer J, Hall A, Farquhar G, eds. Stable isotopes and 590 plant carbon-water relations. New York: Academic Press Inc., 497-510.

591 Lu N. 2016. Generalized soil water retention equation for adsorption and capillarity. Journal of 592 Geotechnical and Geoenvironmental Engineering 142.

593 Mahindawansha A, Orlowski N, Kraft P, Rothfuss Y, Racela H, Breuer L. 2018. 594 Quantification of plant water uptake by water stable isotopes in rice paddy systems. Plant and 595 Soil 429: 281-302.

596 Martín-Gómez P, Barbeta A, Voltas J, Peñuelas J, Dennis K, Palacio S, Dawson TE, Ferrio 597 JP. 2015. Isotope-ratio infrared spectroscopy: A reliable tool for the investigation of plant-water 
sources? New Phytologist 1.

599 Martín-Gómez P, Serrano L, Ferrio JP. 2017. Short-term dynamics of evaporative enrichment 600 of xylem water in woody stems: Implications for ecohydrology. Tree Physiology 37: 511-522.

601 Millar C, Pratt D, Schneider D, McDonnell JJ. 2015. A Comparison of Extraction Systems for 602 Plant Water Stable Isotope Analysis. Rapid Communications in Mass Spectometry: 1-4.

603 Moreno-Gutiérrez C, Dawson TE, Nicolás E, Querejeta JI. 2012. Isotopes reveal contrasting 604 water use strategies among coexisting plant species in a Mediterranean ecosystem. The New 605 phytologist 196: 489-96.

606 Munksgaard NC, Cheesman AW, Wurster CM, Cernusak LA, Bird MI. 2014. Microwave 607 extraction-isotope ratio infrared spectroscopy (ME-IRIS): A novel technique for rapid extraction 608 and in-line analysis of $\delta 180$ and $\delta 2 \mathrm{H}$ values of water in plants, soils and insects. Rapid 609 Communications in Mass Spectrometry 28: 2151-2161.

610 Newberry SL, Nelson DB, Kahmen A. 2017. Cryogenic vacuum artifacts do not affect plant 611 water-uptake studies using stable isotope analysis. Ecohydrology $\mathbf{1 0 .}$

612 Oerter EJ, Bowen GJ. 2019. Spatio-temporal heterogeneity in soil water stable isotopic 613 composition and its ecohydrologic implications in semiarid ecosystems. Hydrological Processes 614 33: $1724-1738$.

615 Oerter E, Finstad K, Schaefer J, Goldsmith GR, Dawson T, Amundson R. 2014. Oxygen 616 isotope fractionation effects in soil water via interaction with cations $(\mathrm{Mg}, \mathrm{Ca}, \mathrm{K}, \mathrm{Na})$ adsorbed 617 to phyllosilicate clay minerals. Journal of Hydrology 515: 1-9.

618 Oerter EJ, Siebert G, Bowling DR, Bowen G. 2019. Soil water vapour isotopes identify 619 missing water source for streamside trees. Ecohydrology 12: 0-1.

620 Orlowski N, Breuer L, Angeli N, Boeckx P, Brumbt C, Cook CS, Dubbert M, Dyckmans J, 621 Gallagher B, Gralher B, et al. 2018. Inter-laboratory comparison of cryogenic water extraction 622 systems for stable isotope analysis of soil water. Hydrology and Earth System Sciences 22: $623 \quad 3619-3637$.

624 Orlowski N, Frede H-G, Brüggemann N, Breuer L. 2013. Validation and application of a 
625 cryogenic vacuum extraction system for soil and plant water extraction for isotope analysis.

626 Journal of Sensors and Sensor Systems 2: 179-193.

627 Penna D, Hopp L, Scandellari F, Allen ST, Benettin P, Beyer M, Geris J, Klaus J, Marshall 628 JD, Schwendenmann L, et al. 2018. Ideas and perspectives: Tracing terrestrial ecosystem water 629 fluxes using hydrogen and oxygen stable isotopes - Challenges and opportunities from an 630 interdisciplinary perspective. Biogeosciences 15: 6399-6415.

631 Poca M, Coomans O, Urcelay C, Zeballos SR, Bodé S, Boeckx P. 2019. Isotope fractionation 632 during root water uptake by Acacia caven is enhanced by arbuscular mycorrhizas. Plant and Soil 633 441: 485-497.

634 R Core Team. 2019. R: A Language and Environment for Statistical Computing.

635 Raulerson SA. 2018. Toward a Diffusive , Non-Destructive Approach to Measuring Stable 636 Isotopes of Water within Tree Stems.

637 Redelstein R, Coners H, Knohl A, Leuschner C. 2018. Water sources of plant uptake along a 638 salt marsh flooding gradient. Oecologia 188: 607-622.

639 Schultz NM, Griffis TJ, Lee X, Baker JM. 2011. Identification and correction of spectral 640 contamination in $2 \mathrm{H} / 1 \mathrm{H}$ and $18 \mathrm{O} / 16 \mathrm{O}$ measured in leaf, stem, and soil water. Rapid 641 Communications in Mass Spectrometry 25: 3360-3368.

642 Stumpp C, Brüggemann N, Wingate L. 2018. Stable isotope approaches in vadose zone 643 research. Vadose Zone Journal 17.

644 Thorburn PJ, Walker GR, Brunel J -P. 1993. Extraction of water from Eucalyptus trees for 645 analysis of deuterium and oxygen-18: laboratory and field techniques. Plant, Cell \& 646 Environment 16: 269-277.

647 Tuller M, Or D. 2005. Water films and scaling of soil characteristic curves at low water 648 contents. Water Resources Research 41: 1-6.

649 Vargas AI, Schaffer B, Yuhong L, Sternberg L da SL. 2017. Testing plant use of mobile vs 650 immobile soil water sources using stable isotope experiments. New Phytologist 215: 582-594.

651 Walker CD, Richardson SB. 1991. The use of stable isotopes of water in characterising the 
source of water in vegetation. Chemical Geology 94: 145-158.

653 Walker GR, Woods PH, Allison GB. 1994. Interlaboratory comparison of methods to 654 determine the stable isotope composition of soil water. Chemical Geology 111: 297-306.

655 Wang J, Fu B, Lu N, Zhang L. 2017. Seasonal variation in water uptake patterns of three plant 656 species based on stable isotopes in the semi-arid Loess Plateau. Science of the Total Environment 657 609: 27-37.

658 Washburn EW, Smith ER. 1934. The isotopic fractionation of water by physiological 659 processes. Science 79: 188-189.

660 Wassenaar LI, Hendry MJ, Chostner VL, Lis GP. 2008. High resolution pore water $\delta 2 H$ and $661 \delta 18 \mathrm{O}$ measurements by $\mathrm{H} 2 \mathrm{O}$ (liquid)-H2O (vapor) equilibration laser spectroscopy. 662 Environmental Science and Technology 42: 9262-9267.

663 White J, Cook E, Lawrence J, Broecker W. 1985. The D/H Ratios of Sap in Trees 664 Implications for Water Sources and Tree-Ring D/H Ratios. Geochimica Et Cosmochimica Acta 665 49: 237-246.

666 Yakir D, Ting I, DeNiro M. 1994. Natural Abundance 2H/1H Ratios of Water Storage in 667 Leaves of Peperomia Congesta HBK during Water Stress. Journal of Plant Physiology 144: 607668612.

669 Zhao L, Wang L, Cernusak LA, Liu X, Xiao H, Zhou M, Zhang S. 2016. Significant 670 Difference in Hydrogen Isotope Composition Between Xylem and Tissue Water in Populus 671 Euphratica. Plant Cell and Environment 39: 1848-1857.

672 Zimmermann U, Ehhalt D, Münnich KO. 1967. Soil-water movement and evapotranspiration: 673 changes in the isotopic composition of the water. In: Isotopes in hydrology: Proceedings of a 674 symposium. Vienna: International Atomic Energy Agency, 576-585. 
682 Table 1. Output of the stepwise regression models for the soil-plant isotopic offsets. Effects 683 include VWC relative to VWC at the permanent wilting point $\left(\theta_{\text {rel }}\right)$, leaf midday water potential $684\left(\Psi_{m d}\right)$ and the daily difference between predawn and midday water potential $(\Delta \Psi)$. 'Std. Error' 685 corresponds to the standard error of the mean.

686

\begin{tabular}{|c|l|r|r|r|r|r|}
\hline & & Estimate & Std. Error & \multicolumn{1}{c|}{$t$-value } & \multicolumn{1}{c|}{$P$-value } & \multicolumn{1}{c|}{$R^{2}$} \\
\hline \multirow{3}{*}{$\Delta^{18} \mathrm{O}$} & Intercept & 0.12 & 0.43 & 0.76 & 0.79 & \\
\cline { 2 - 7 } & $\theta_{\text {rel }}$ & -2.59 & 1.01 & -2.56 & 0.01 & 0.08 \\
\cline { 2 - 7 } & $\Psi_{\text {md }}$ & 0.81 & 0.19 & 4.32 & $<0.0001$ & 0.19 \\
\cline { 2 - 7 } & $\Delta \Psi$ & 1.57 & 0.28 & 5.60 & $<0.0001$ & 0.24 \\
\hline \multirow{3}{*}{$\Delta^{2} \mathrm{H}$} & Model $R^{2}$ & & & & & 0.36 \\
\cline { 2 - 8 } & Intercept & 6.36 & 2.27 & 2.81 & $<0.01$ & \\
\cline { 2 - 7 } & $\theta_{\text {rel }}$ & 3.87 & 5.30 & 0.73 & 0.47 & 0.007 \\
\cline { 2 - 7 } & $\Psi_{\text {md }}$ & 5.91 & 0.98 & 6.05 & $<0.0001$ & 0.32 \\
\cline { 2 - 7 } & $\Delta \Psi$ & 9.6 & 1.47 & 6.55 & $<0.0001$ & 0.36 \\
\hline & Model $R^{2}$ & & & & & 0.55 \\
\hline
\end{tabular}




\section{Figure captions}

690 Figure 1. Illustration of the expected isotopic composition of bulk soil $\left(\delta_{\text {soil }}\right)$ and stem $\left(\delta_{\text {stem }}\right)$

691 water when irrigation ( $P$, with a constant isotopic composition $\left.\delta_{\mathbf{P}}\right)$ continuously 692 compensates root water uptake $(U)$ and transpiration $(T)$, and evaporation losses are 693 negligible (i.e. control treatments). (a) scenario when root water uptake fractionates water 694 isotopes (fractionation factor $\varepsilon_{U}$ ) and (b) scenario when adsorbed water in the soil (fraction $\mathrm{f}_{\mathrm{a}}$ ) 695 and the stem's storage tissue water (fraction $\mathrm{f}_{\mathrm{x}}$ ) are depleted with respect to mobile and capillary 696 water in the soil (fractionation $\boldsymbol{\varepsilon}_{\mathrm{a}}$ ) and the xylem's vessel water(fractionation $\boldsymbol{\varepsilon}_{\mathrm{x}}$ ).

697 Figure 2. Time course of soil and plant water status over the experiment. Mean soil 698 gravimetric water content (GWC), leaf predawn water potential $\left(\Psi_{\mathrm{pd}}\right)$, plant water content (roots 699 and stems) and stomatal conductance $\left(g_{\mathrm{s}}\right)$ over the course of the experiment in control (left 700 panels) and drought (right panels) treatments. Error bars are the standard error of the mean $701 \quad\left(N=30\right.$ and 15 , for soil GWC and 15 and 9 for $\Psi_{\mathrm{pd}}$, plant GWC and $g_{\mathrm{s}}$ for drought and control, 702 respectively).

703 Figure 3. Time course of soil and plant water isotopic composition over the experiment.

704 Mean $\delta^{2} \mathrm{H}$ and $\delta^{18} \mathrm{O}$ of soil, stem and root water over the course of the experiment in control (left 705 panels) and drought (right panels) treatments. Error bars are the standard error of the mean $(N=$ 70615 and 9, for drought and control, respectively) and can be masked by the symbol when too 707 small. The solid teal line corresponds to the mean of the isotopic composition of the irrigation 708 water and the dashed lines its standard error. Vertical arrows in the top panels indicate irrigation 709 times. On right panels, the vertical dashed line indicates the approximate time when the drought 710 treatment started to have significant effects on plant water status (Fig. 1).

711 Figure 4. Dual isotope representation $\left(\delta^{12} \mathbf{H}\right.$ and $\left.\delta^{18} \mathbf{O}\right)$ of soil, stem and root water. (a) 712 Control treatment. (b) Drought treatment. Blue triangles indicate the isotopic composition of 713 irrigation water during the experiment and the dotted line represents the local meteoric water 714 line.

715 Figure 5. Correlations between soil-plant $\boldsymbol{\delta}^{\mathbf{1 8}} \mathbf{O}$ and $\boldsymbol{\delta}^{\mathbf{2}} \mathbf{H}$ offsets. (a) soil-stem offsets. (b) 716 soil)root offsets. 
717 Figure 6. Effect of soil moisture on water isotopic compositions. Relationships between $\theta_{\text {rel }}$

718 (soil VWC relative to VWC at the permanent wilting point) and soil water $\delta^{2} \mathrm{H}$ and $\delta^{18} \mathrm{O}$ (left

719 panels), stem water $\delta^{2} \mathrm{H}$ and $\delta^{18} \mathrm{O}$ (middle panels) and the soil-stem isotopic offsets $\Delta^{18} \mathrm{O}$ and

$720 \Delta^{2} \mathrm{H}$ (right panels). Data were averaged by sampling date and irrigation and VPD treatments.

721 Error bars are standard errors of the mean, and the dashed line indicates the isotopic composition

722 of irrigation water (left and middle panels) or the zero (right panels).

723 Figure 7. Effect of plant $\Delta \Psi$ on water isotopic compositions. Relationships between plant $\Delta \Psi$

724 (daily difference between $\Psi_{\mathrm{pd}}$ and $\Psi_{\mathrm{md}}$ ) and soil water $\delta^{2} \mathrm{H}$ and $\delta^{18} \mathrm{O}$ (left panels), stem water $\delta^{2} \mathrm{H}$

725 and $\delta^{18} \mathrm{O}$ (middle panels) and soil-stem isotopic offsets $\Delta^{18} \mathrm{O}$ and $\Delta^{2} \mathrm{H}$ (right panels). Data were

726 averaged by sampling date, and irrigation and VPD treatments. Error bars are standard errors of

727 the mean, and the dashed line indicates the isotopic composition of irrigation water (left and

728 middle panels) or the zero (right panels).

729 Figure 8. Illustration of the proposed effects on the isotopic composition ( $\delta$ ) of bulk soil $730\left(\delta_{\text {soil }}\right)$ and stem $\left(\delta_{\text {stem }}\right)$ water in the present experiment, where soil $\left(E_{\text {soil }}\right)$ and stem $\left(E_{\text {stem }}\right)$ 731 evaporation are not fully suppressed. (a) Control treatment with regular irrigation $(P$ with 732 constant isotopic composition, $\delta_{\mathrm{P}}$ ) compensating water losses through $E_{\text {soil }}$ and root water uptake 733 ( $U$, further lost via transpiration $T$ and $E_{\text {stem}}$ ). Here, the isotopic composition of soil mobile and 734 capillary water $\left(\delta_{\mathrm{m}}\right)$ and water inside the xylem vessels are expected to reflect $\delta_{\mathbf{P}}$ with a possible 735 enrichment due to soil evaporation occurring between irrigations events $\left(\geq \delta_{\mathbf{P}}\right)$, while soil 736 capillary water (fraction $\mathrm{f}_{\mathrm{a}}$ ) and stem storage tissue water (fraction $\mathrm{f}_{\mathrm{x}}$ ) are depleted with respect 737 to mobile soil water (fractionation $\boldsymbol{\varepsilon}_{\mathrm{a}}$ ) and to water inside the xylem conduits (fractionation $\boldsymbol{\varepsilon}_{\mathrm{x}}$ ). 738 (b) Drought treatment with water losses via $T, E_{\text {soil }}$ and $E_{\text {stem }}$ not being compensated with $P$. 739 Here, $\delta_{\mathrm{m}}$ becomes progressively more enriched (due to soil evaporative enrichment) while the 740 fraction of soil capillary water $\left(\mathrm{f}_{\mathrm{a}}\right)$ increases. Resulting $\delta_{\text {soil }}$ either becomes more enriched 741 (following $\delta_{\mathrm{m}}$ ) or more depleted (following $\mathrm{f}_{\mathrm{a}}$ ), depending on the balance between the two 742 processes. Meanwhile, $\delta_{\text {stem }}$ becomes progressively more enriched, following $\delta_{m}$ because $f_{x}$ 743 varies proportionally less than $\mathrm{f}_{\mathrm{a}}$ along the experiment (Fig. 2). 


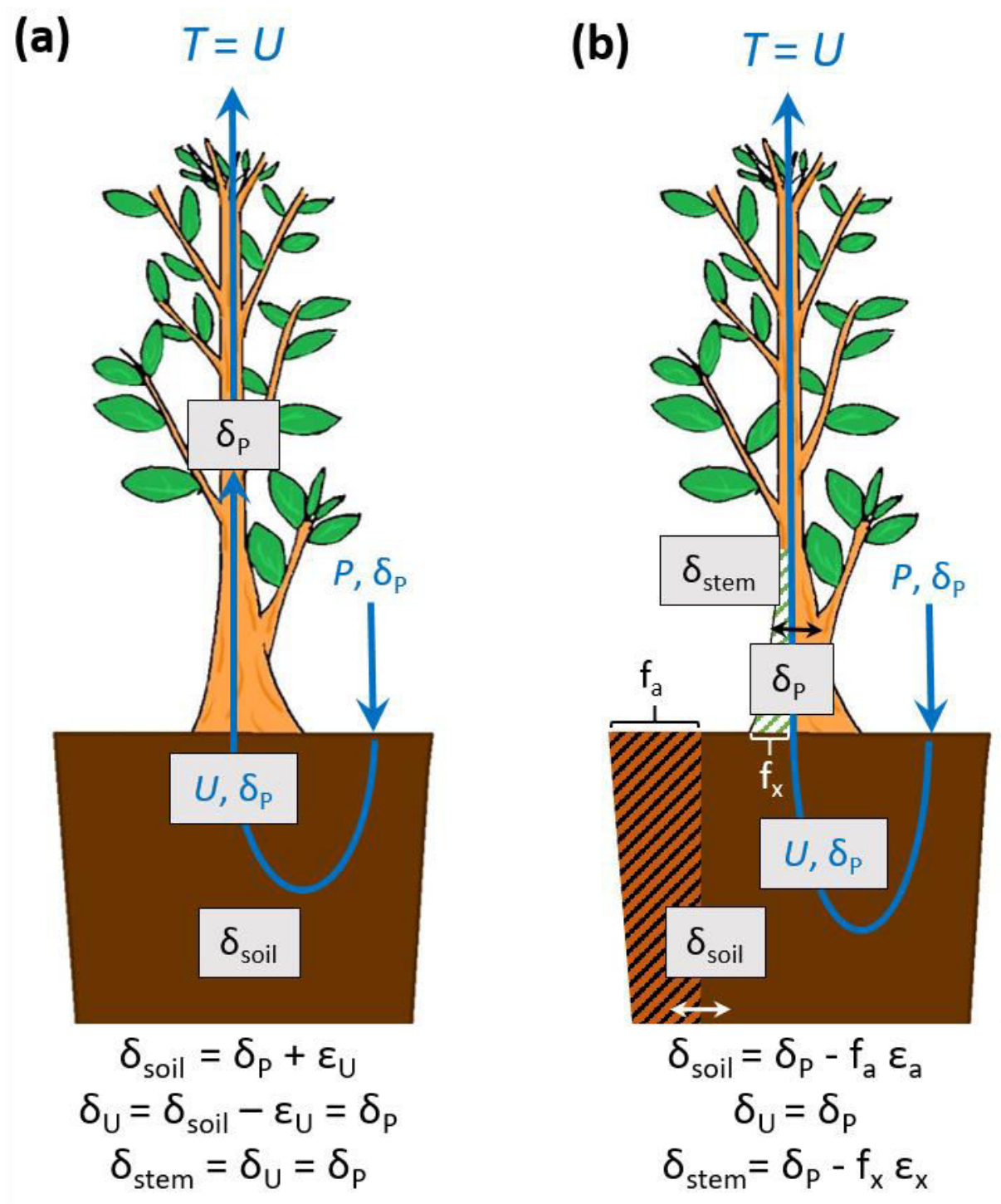




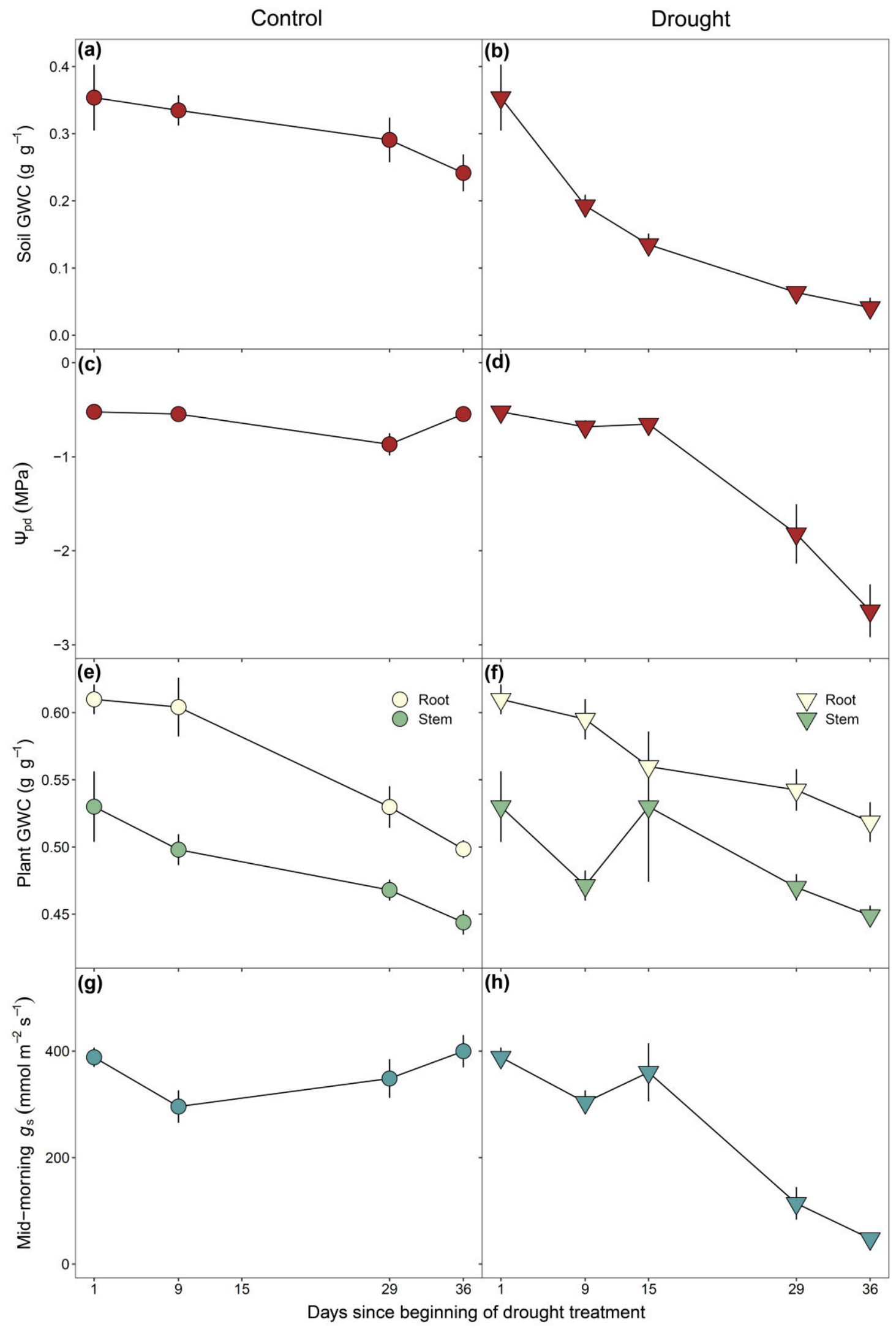




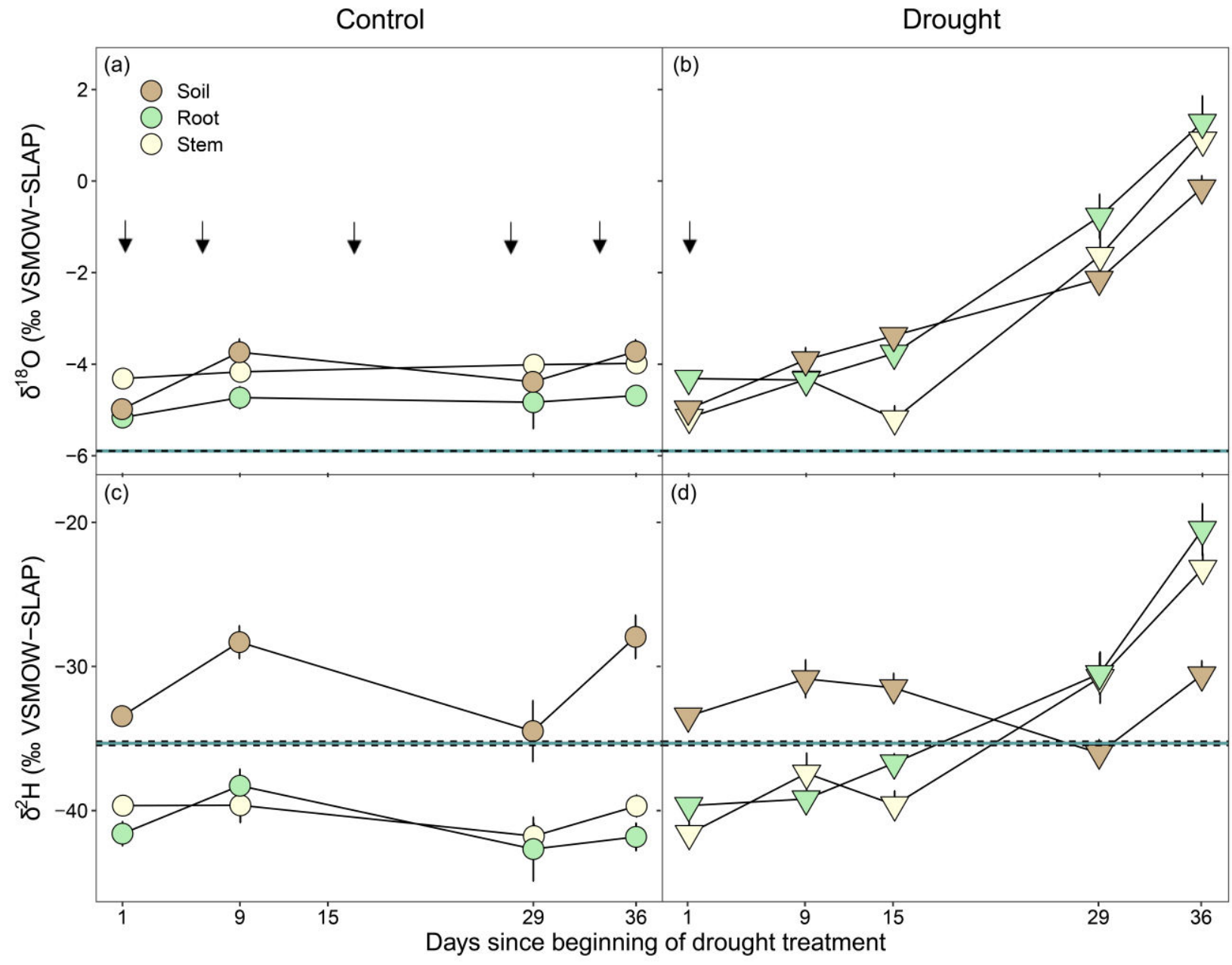

758 

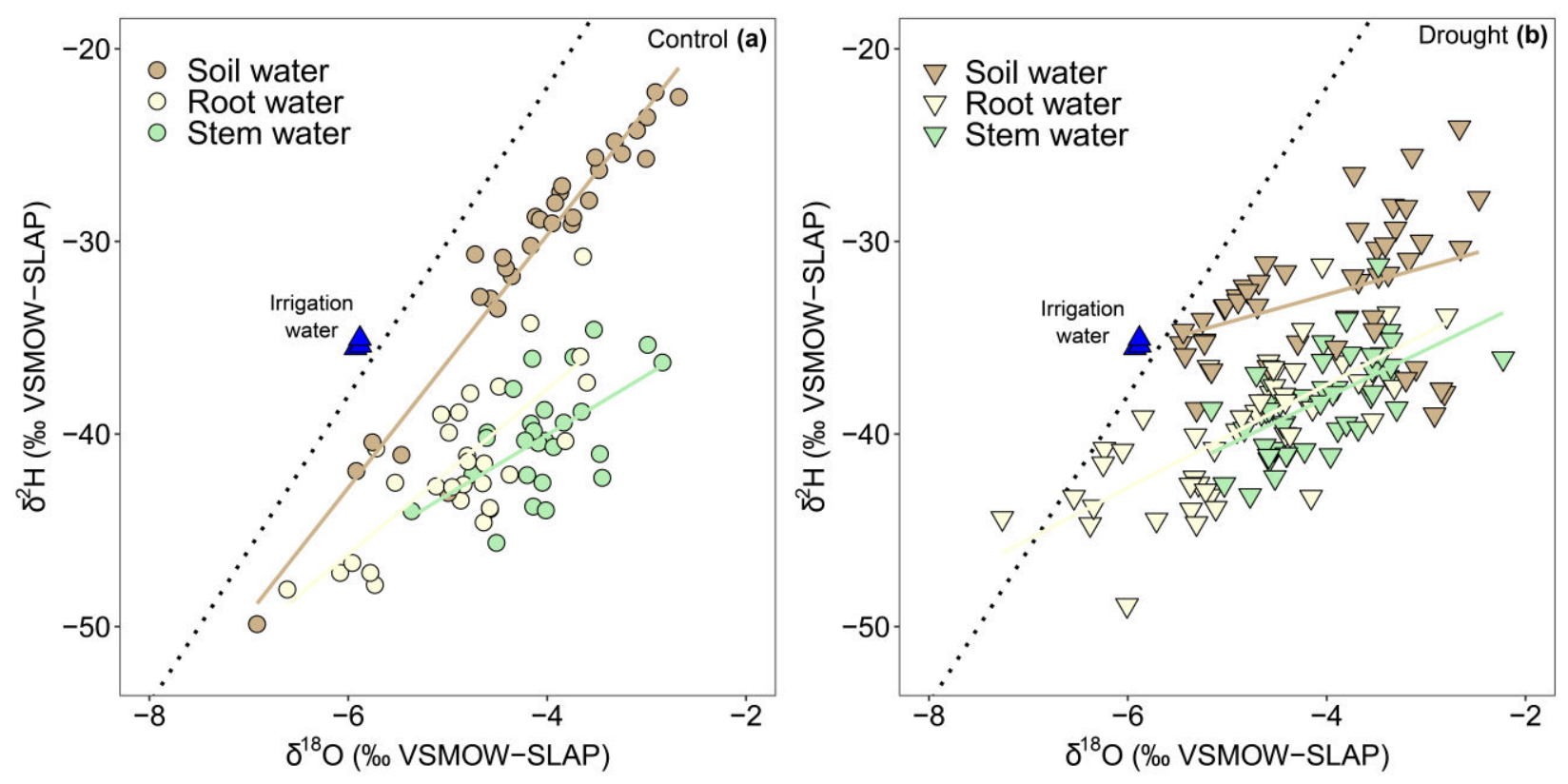

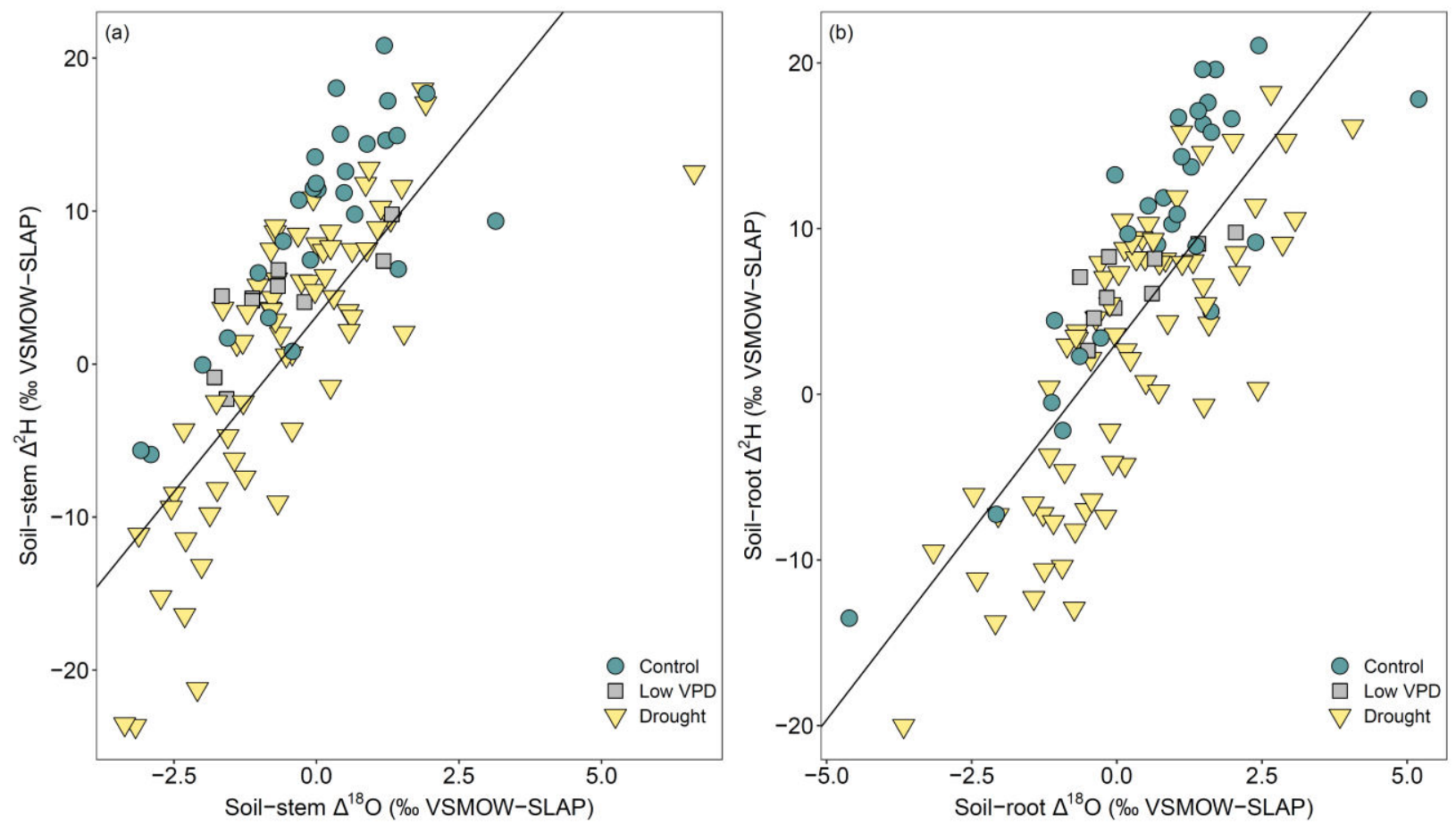

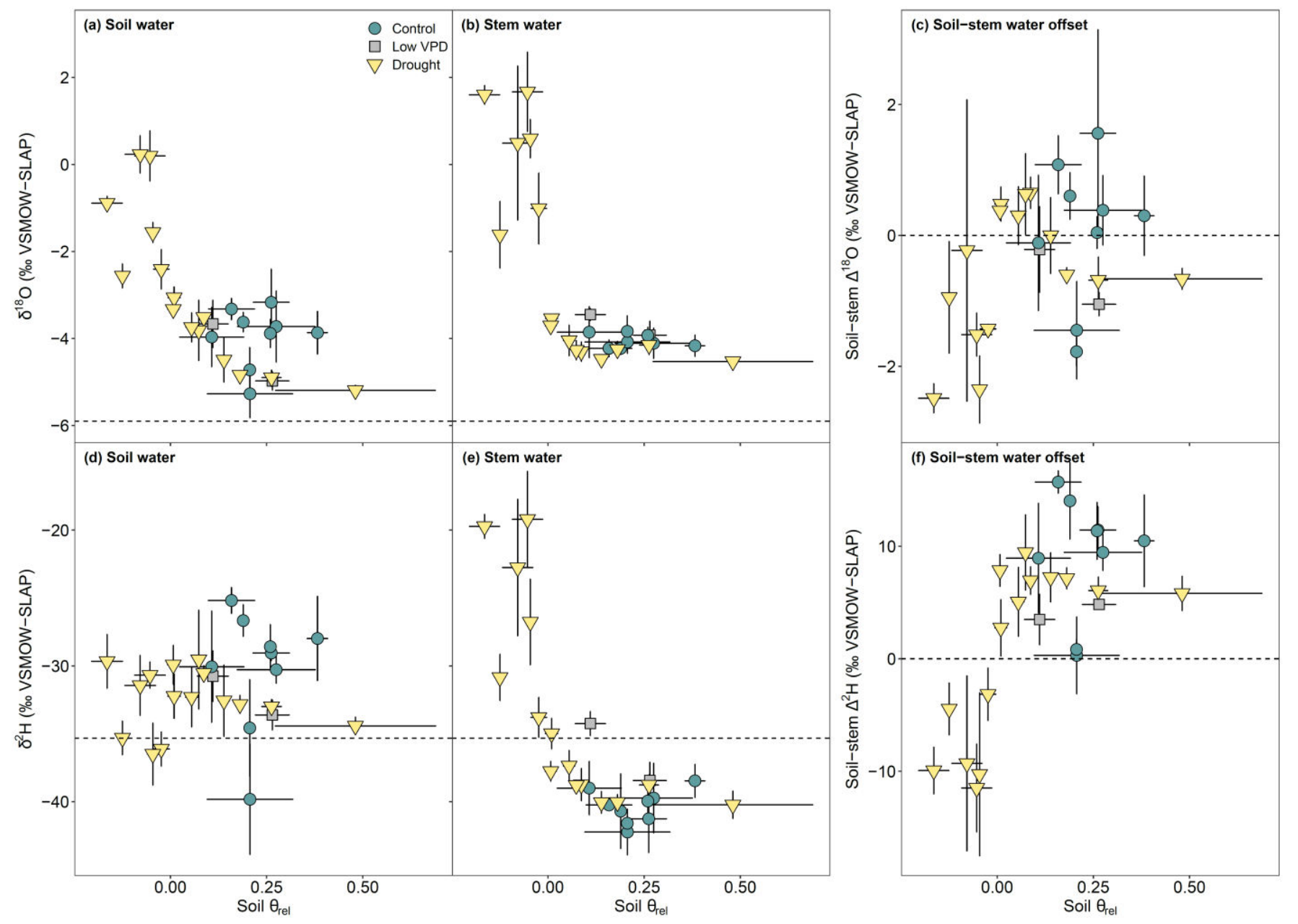

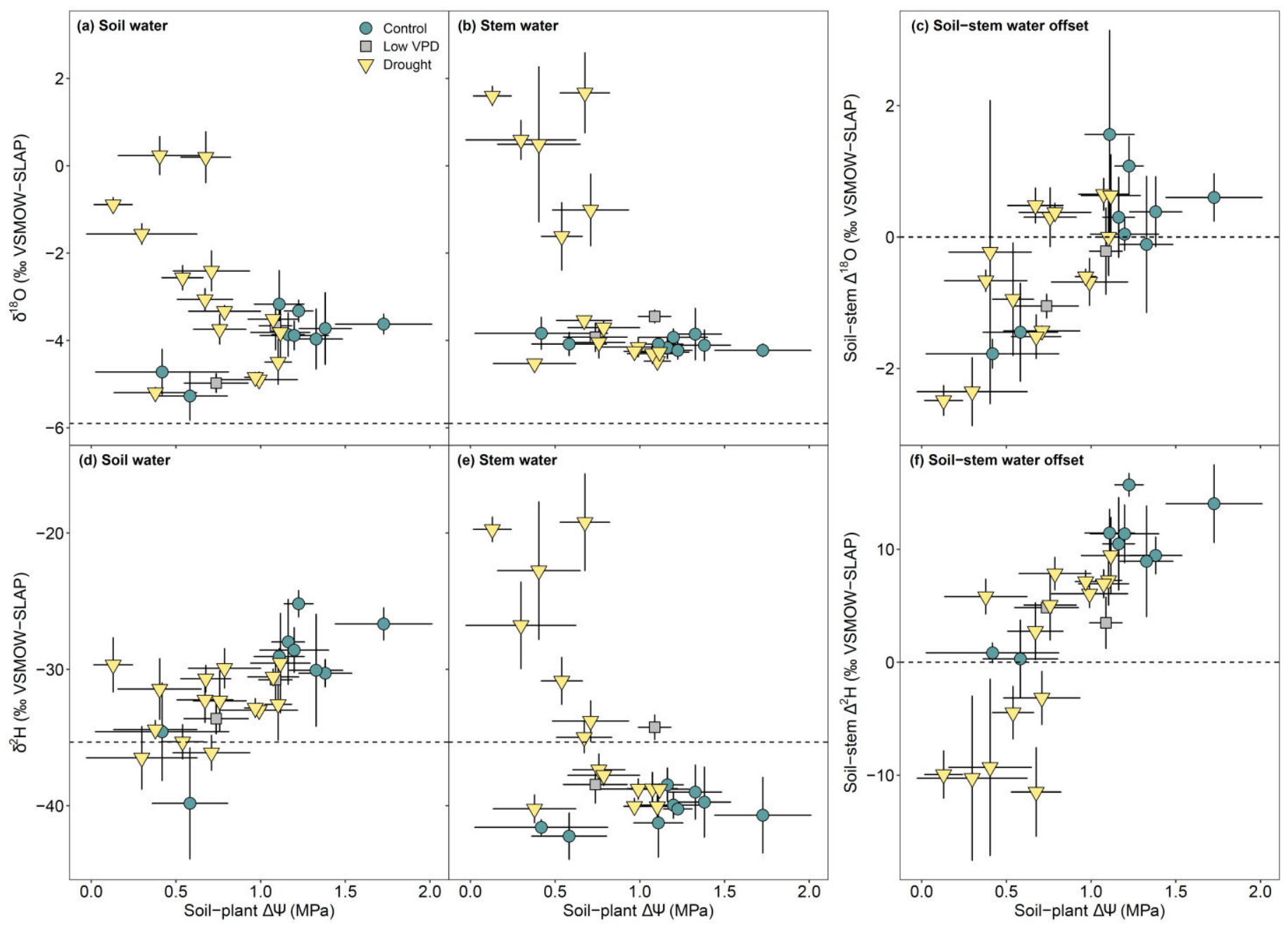


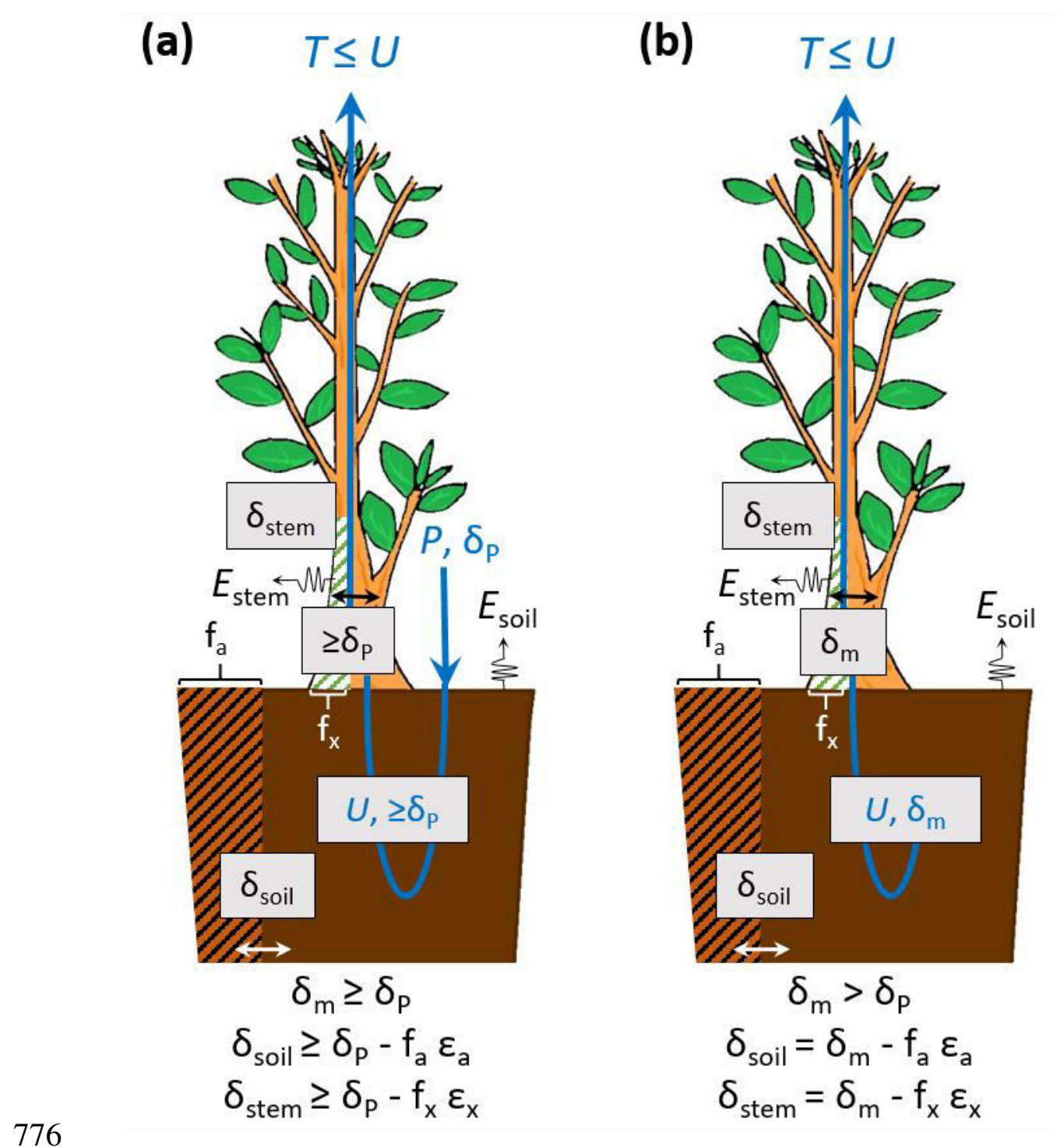

777

778

779 


\section{New Phytologist Supporting Information}

Article title: An explanation for the isotopic offset between soil and stem water in a temperate tree species

Authors: Adrià Barbeta, Teresa E. Gimeno, Laura Clavé, Bastien Fréjaville, Sam P. Jones, Camille Delvigne, Lisa Wingate, Jérôme Ogée

Article acceptance date: Click here to enter a date.

The following Supporting Information is available for this article:

Fig. S1 Soil water retention curves.

Fig. S2 Soil gravimetric water contents and predawn leaf water potentials.

Fig. S3 Midday leaf water potentials and daily amplitude in leaf water potentials.

Fig. S4 Isotopic composition of water pools in the different soils.

Fig. S5 Soil-stem and soil-root isotopic offsets.

Fig. S6 Effect of the low VPD treatment on soil-stem isotopic offsets.

Fig. S7 Effect of leaf stomatal conductance on soil and stem water isotopic compositions.

Fig. S8 Effect of midday leaf water potential on soil and stem water isotopic compositions.

Notes S1 Sensitivity analysis on the control treatment.

Fig. S9 Effect of soil evaporation on the theoretical isotope ratios of soil and stem water.

Fig. S10 Boxplot of the temporal course of soil and plant conditions.

Fig. S11 Boxplot of the temporal course of the isotopic composition of soil and plant water. 
Figure S1. Soil water retention curves for three soils used in this experiment. Note the different scales in the $x$-axis.

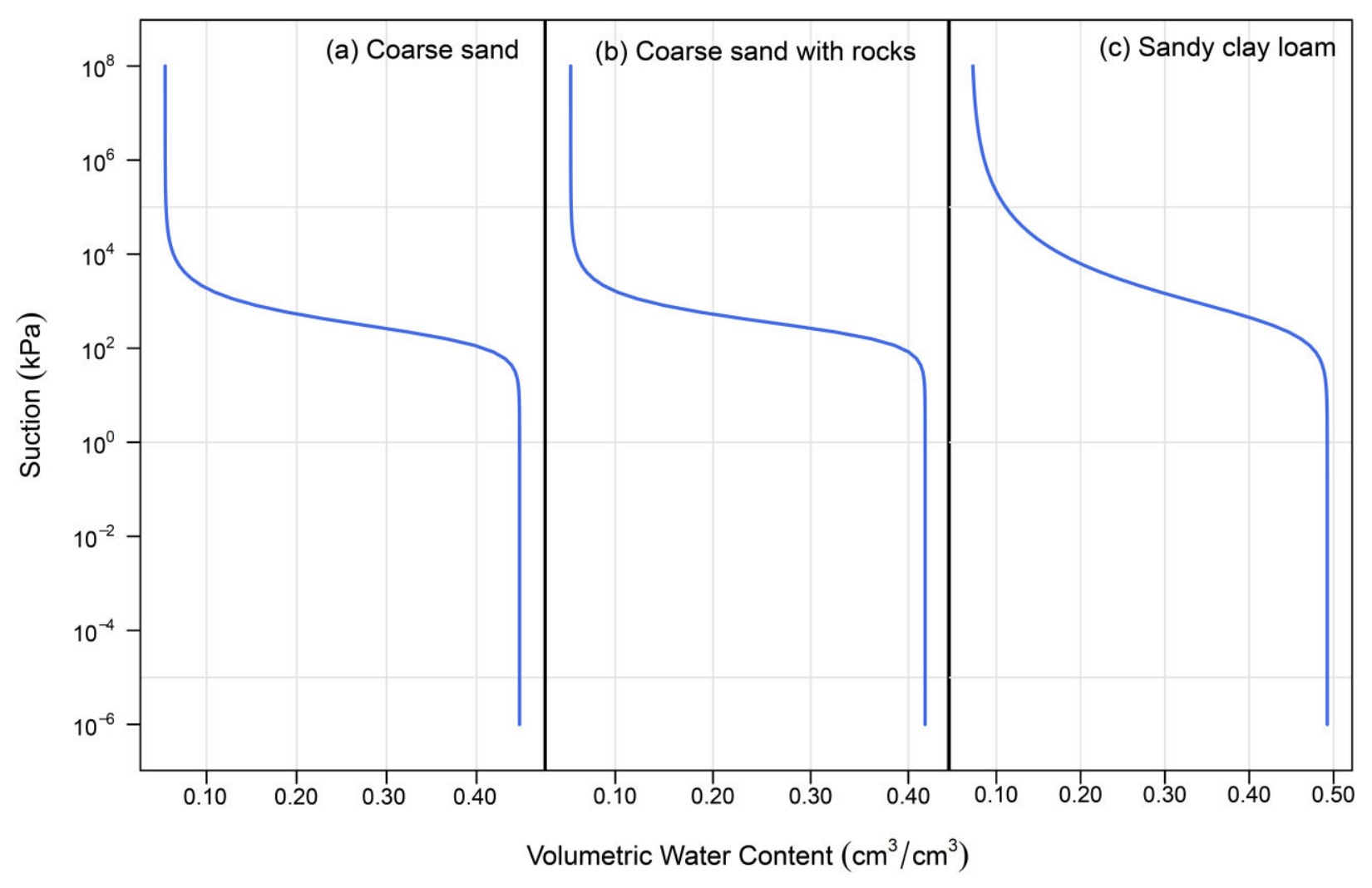


Figure S2. Boxplots of the soil volumetric water content (VWC, a and b) and predawn leaf water potential ( $\Psi_{\mathrm{pd}}, \mathrm{c}$ and $\left.\mathrm{d}\right)$ in control (a and $\mathrm{c}$ ) and drought-stressed pots ( $\mathrm{b}$ and d), for each soil type, over the course of the experiment. Boxplots show the interquartile range, the median (black line), the minimum and the maximum values (whiskers) besides outliers (black dots), with $\mathrm{N}=10$ and 5 , for $\mathrm{VWC}$ and 5 and 3 for $\Psi_{\mathrm{pd}}$, for drought and control, respectively.

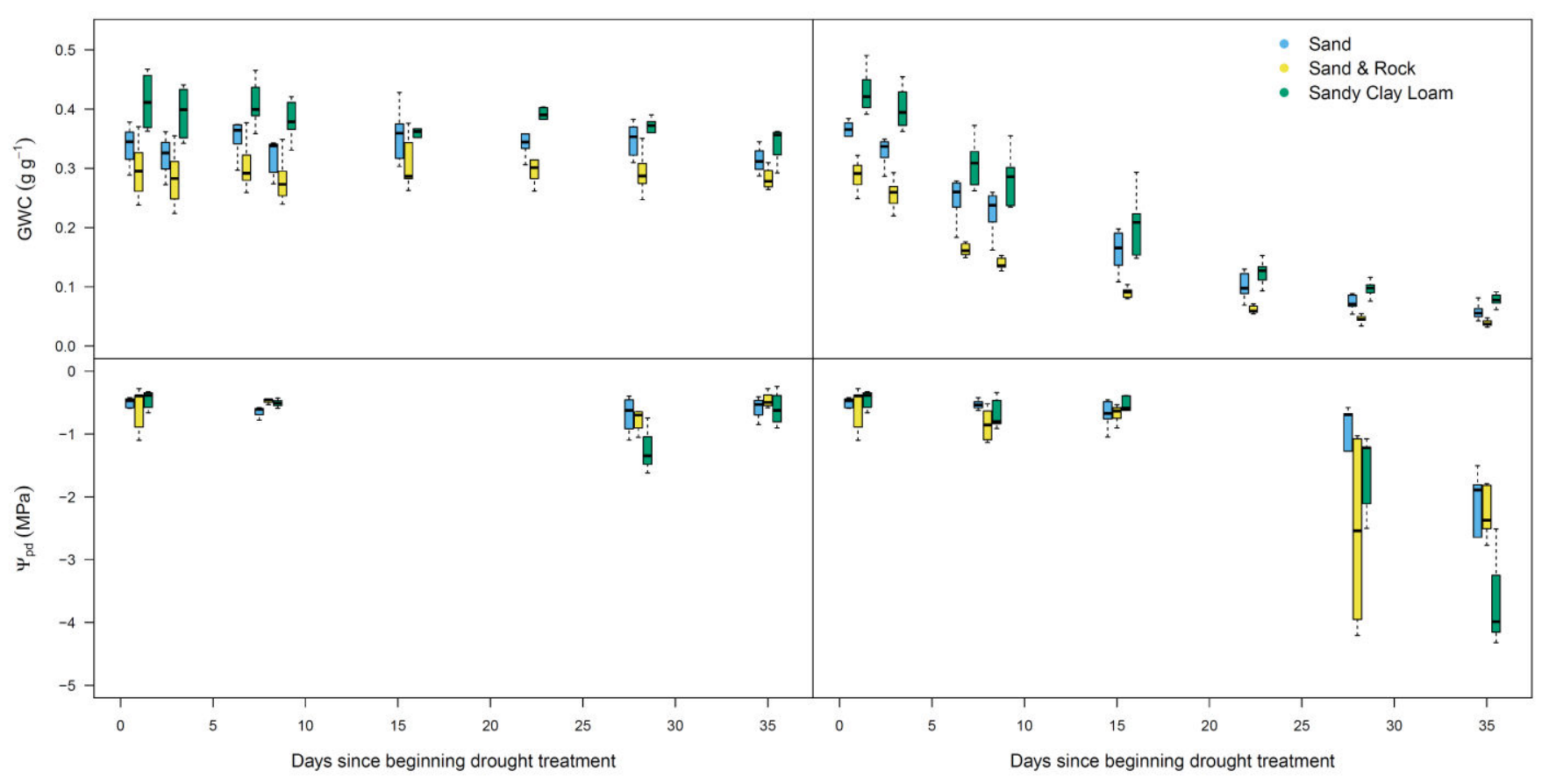


Figure S3. Midday leaf water potential $\left(\Psi_{\mathrm{md}}\right.$, a and b) and difference between predawn and midday $\Psi\left(\Delta \Psi_{\mathrm{pd}-\mathrm{md}}, \mathrm{c}\right.$ and d) over the course of the experiment in control (a and c) and drought (b and d) treatments. Boxplots show the interquartile range, the median (black line), the minimum and the maximum values (whiskers) besides outliers (black dots), with $N=15$ and 9 for drought and control, respectively).
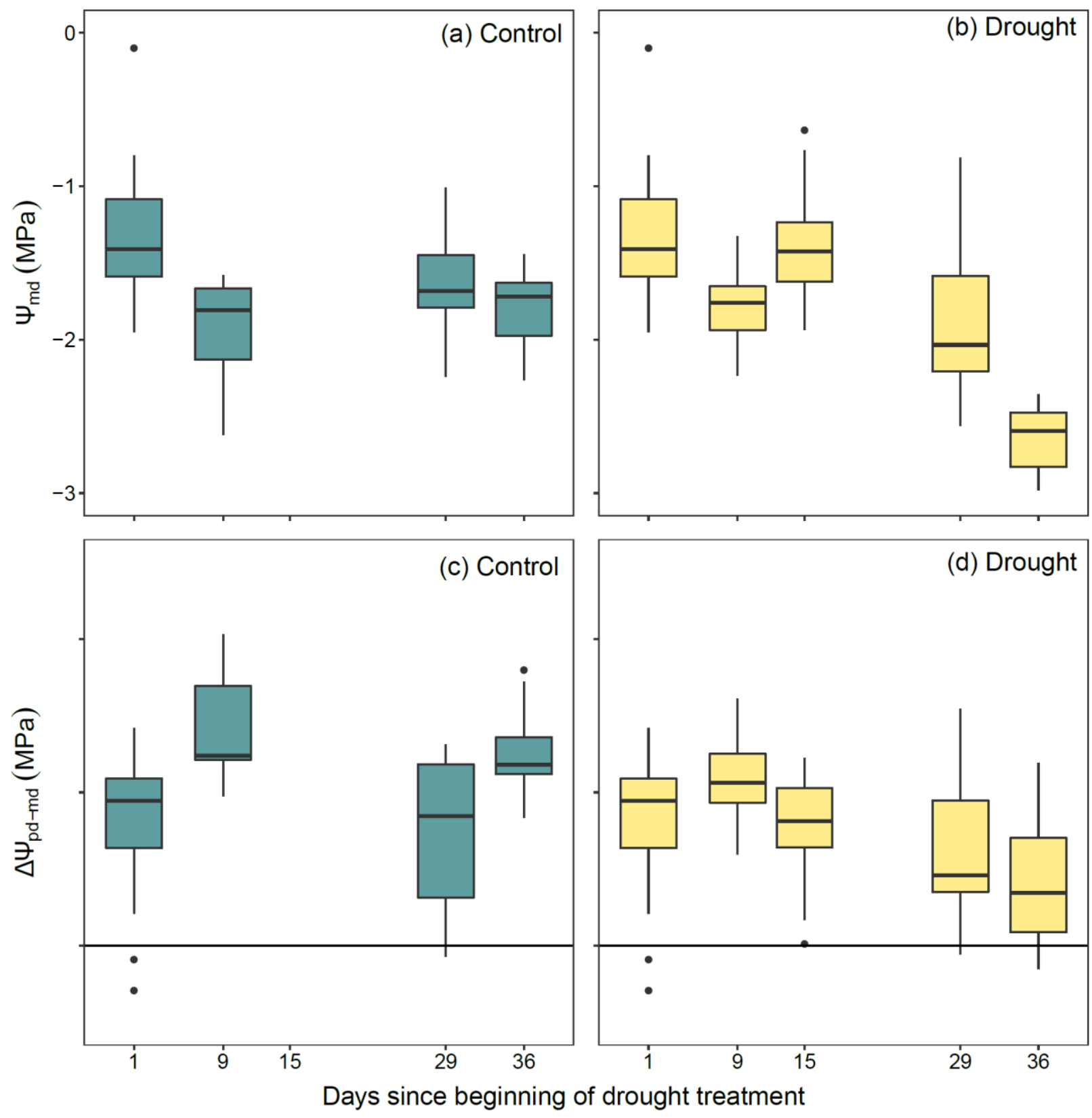

Figure S4. Isotopic composition $\left(\delta^{2} \mathrm{H}\right.$ and $\left.\delta^{18} \mathrm{O}\right)$ of soil, stem, root and rock water over the course of the experiment only in the drought treatments pots, and split by soil texture as follows: coarse sand (a, d), coarse sand with rocks (b, e) and sandy clay loam (c, e). The teal line corresponds to the mean of the isotopic composition of the irrigation water and the dashed blue lines are the span of the standard error of the mean. Boxplots show the interquartile range, the median (black line), the minimum and the maximum values (whiskers) besides outliers (black dots), with $=5$ and 3 , for drought and control, respectively.
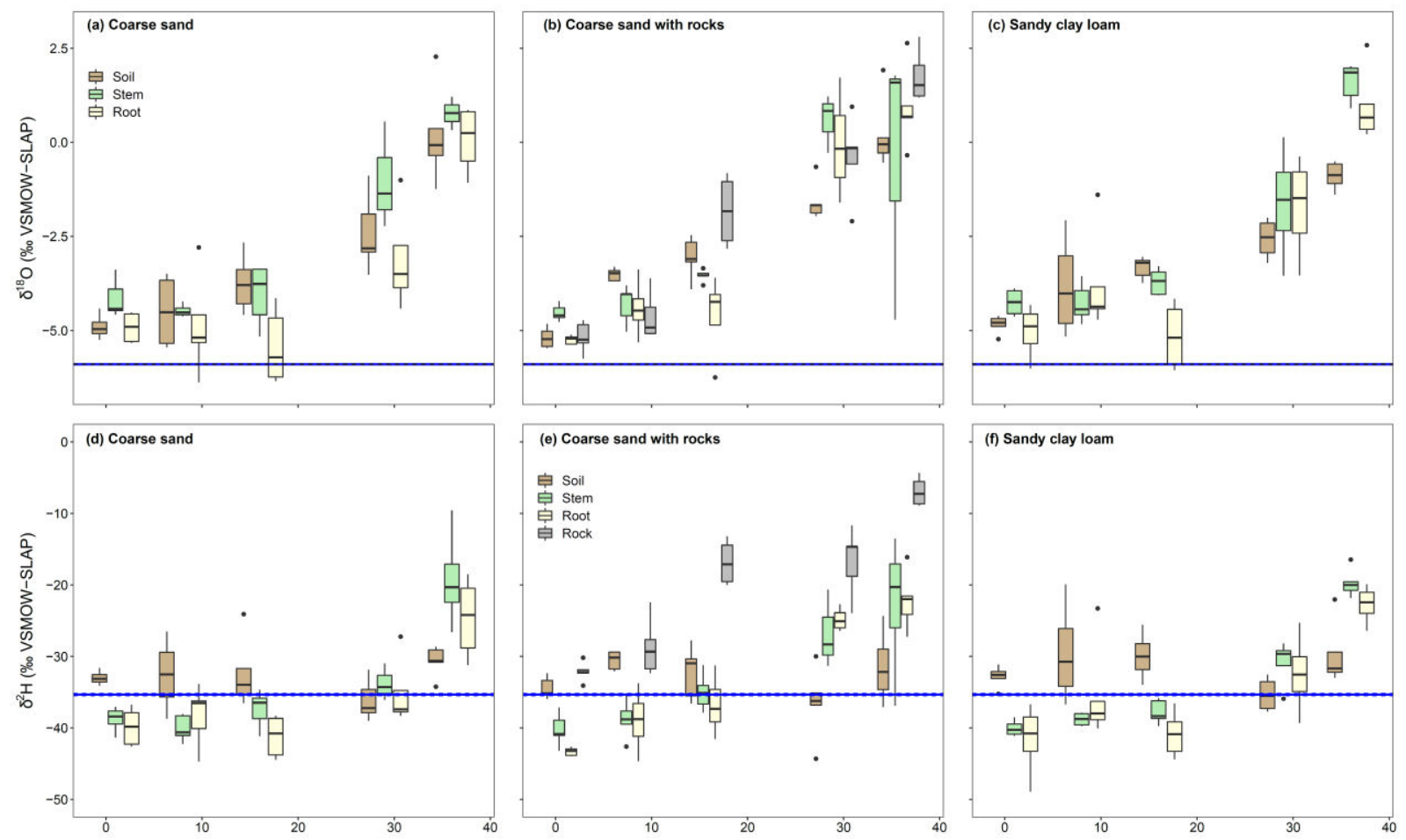
Figure S5. Soil-stem water isotopic offsets $\left(\Delta^{18} \mathrm{O}\right.$ (a) and $\Delta^{2} H$ (c)) over the course of the experiment in control (teal boxes) and drought (yellow boxes) treatment and the same for soilroot isotopic offsets $\left(\Delta^{18} \mathrm{O}(\mathrm{b})\right.$ and $\left.\Delta^{2} \mathrm{H}(\mathrm{d})\right)$. Error bars are the standard error of the mean $(N=$ 15 and 9, for control and drought, respectively). Note that control pots were not sampled in the third sampling campaign.
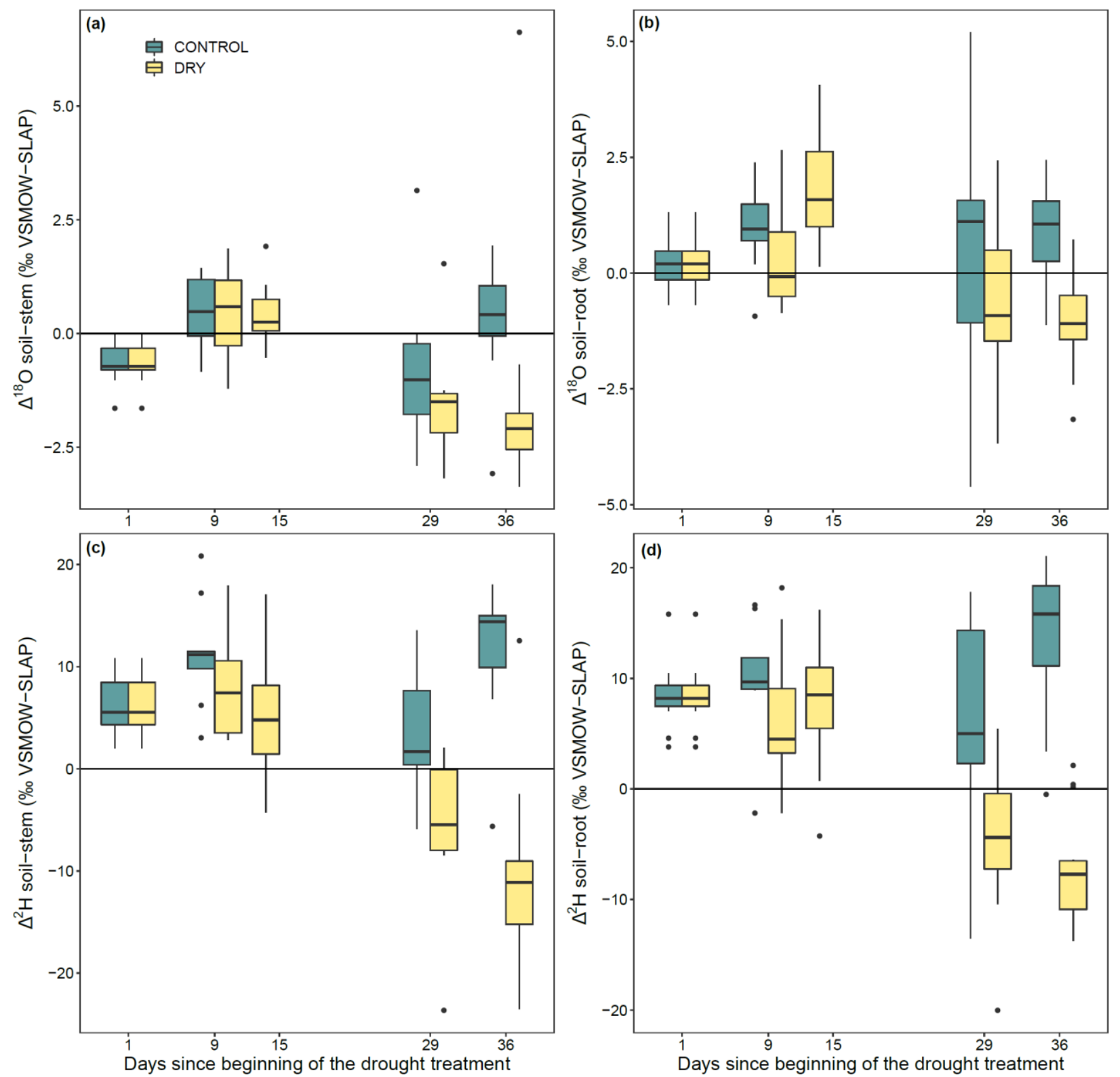
Figure S6. Effect of the VPD treatment (low (blue boxes) or ambient (orange boxes)) on soilstem isotopic offsets $\left(\Delta^{18} \mathrm{O}(\mathrm{a})\right.$ and $\left.\Delta^{2} \mathrm{H}(\mathrm{b})\right)$. Box heights correspond to the $1^{\text {st }}-3^{\text {rd }}$ interquartile, the line inside the box is the value of the median, whiskers correspond to the minimum and maximum values within 1.5 times the interquartile range and data beyond 1.5 times the interquartile range are points outside the whiskers. Significant differences are highlighted with an asterisk $(P<0.05)$.
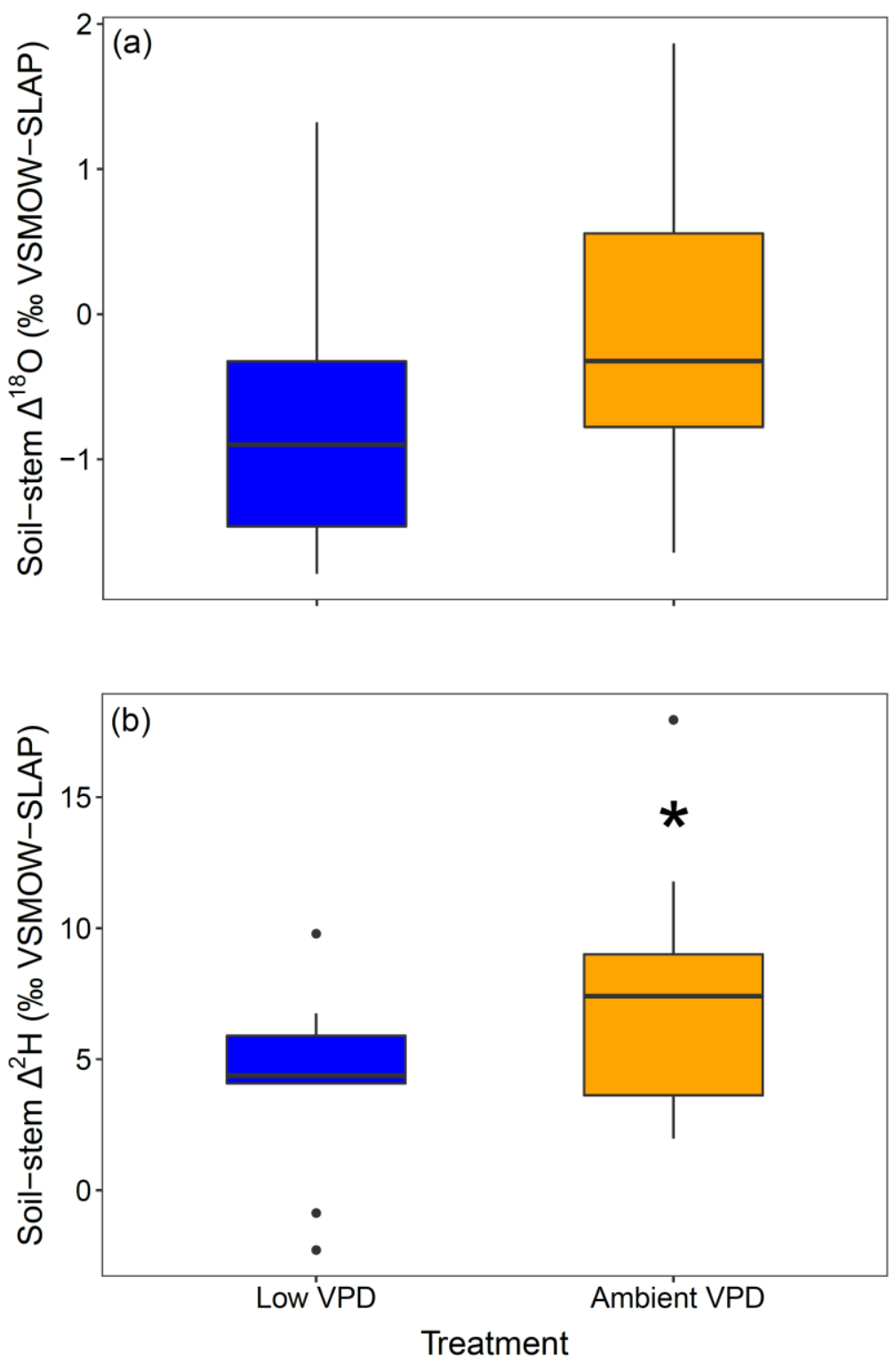
Figure S7. Relationships between the soil and plant isotopic composition $\left(\delta^{18} \mathrm{O}(\mathrm{a})\right.$ and $\left.\delta^{2} \mathrm{H}(\mathrm{b})\right)$ groups of soil, watering and VPD treatments and stomatal conductance at midday. Error bars are standard errors of the mean, and the dashed line indicates the isotopic composition of irrigation water.

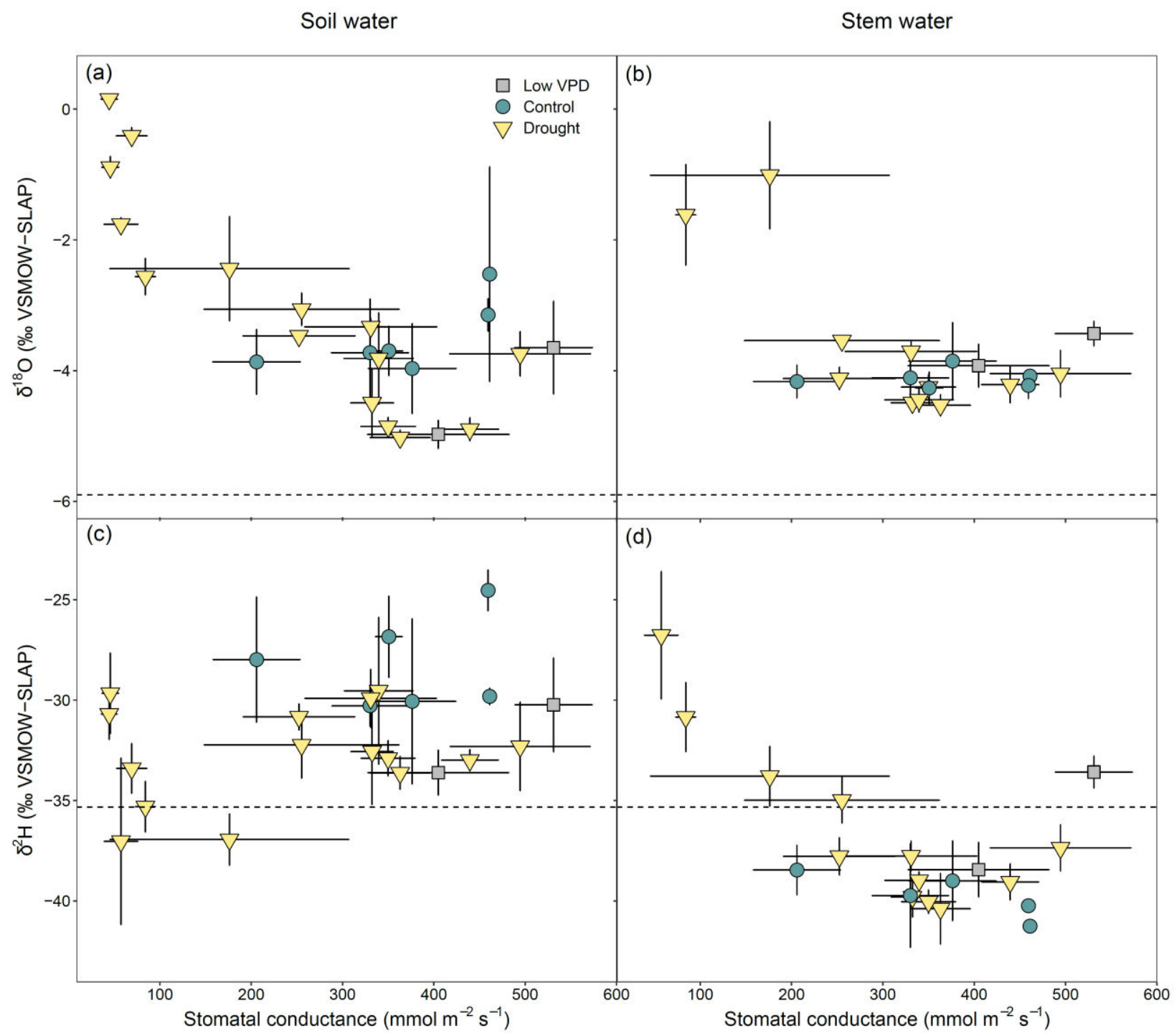


Figure S8. Relationships between the soil and plant isotopic composition groups $\left(\delta^{18} \mathrm{O}(\mathrm{a})\right.$ and $\left.\delta^{2} \mathrm{H}(\mathrm{b})\right)$ of soil, watering and VPD treatments and twig water potentials at midday $\left(\Psi_{\mathrm{md}}\right)$. Error bars are standard errors of the mean, and the dashed line indicates the isotopic composition of irrigation water.

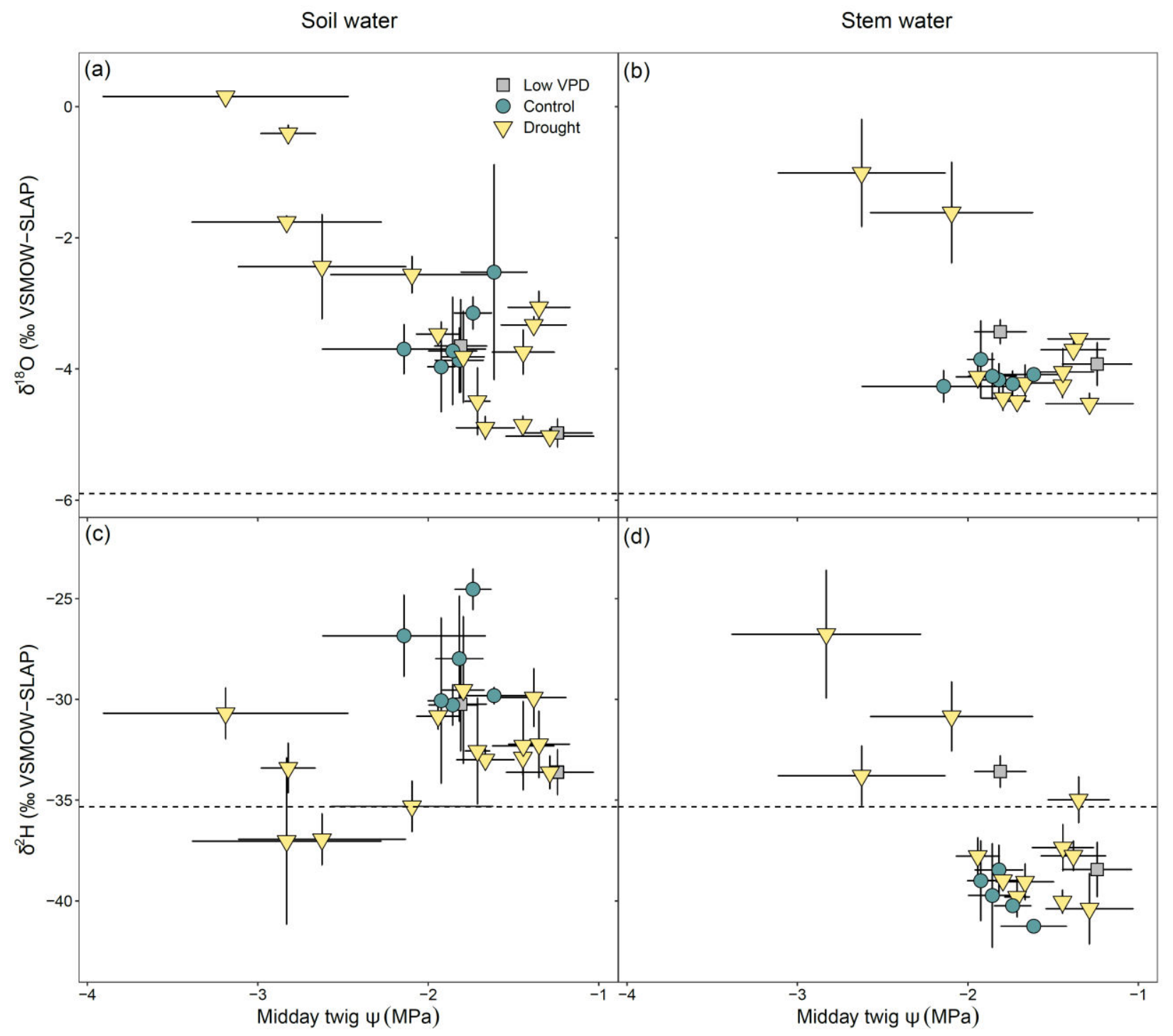


Notes S1. Sensitivity analysis on the control treatment.

In this section, we explore the possible effects of isotopic fractionation during root water uptake and soil evaporation $\left(\alpha_{E}\right)$ on the isotopic composition of soil and stem (xylem) water, under nearly continuous irrigation, transpiration and evaporation. This approximates the situation in our control treatments, whereby evapotranspiration losses were compensated with regular irrigation to ensure that soil moisture content remained the same throughout the experiment.

First we considered the simplest situation where soil evaporation is fully supressed (i.e. the purpose of the plastic covers used to cover the soils in our experiment) and irrigation is added daily to compensate for the soil water taken up by roots (for practical reasons, irrigation was applied only every 3 days in our control treatment but this does not change the reasoning below). In this situation, if there is fractionation during root water uptake (say of $3 \%$, i.e. with a fractionation factor $\alpha_{U}=0.997<1$ ), then for every day when water is added with an isotope ratio $R_{\mathrm{P}}$, the same amount is removed by root water uptake with an isotope ratio $\alpha_{\mathrm{U}} R_{\mathrm{S}}<R_{\mathrm{S}}$, where $R_{\mathrm{S}}$ is the isotope ratio of soil water (we neglect possible soil water isotope gradients with soil depth or distance to the rhizosphere for the moment). In other words, transpiration takes relatively fewer heavy water isotopes than there are in the soil, thus soil water becomes enriched in the heavy isotopes, whilst irrigation either enriches or depletes soil water depending if $R_{\mathrm{P}}>R_{\mathrm{s}}$ or not. Over time, the isotope ratio of soil water $\left(R_{\mathrm{s}}\right)$ changes until it reaches its steady-state (s.s.) value: $R_{\mathrm{s}}$ (s.s.) $=R_{\mathrm{P}} / \alpha_{\mathrm{U}}$. In this situation, both fluxes into and out of the soil have the same isotopic signature because irrigation adds water to the soil with the composition $R_{\mathrm{P}}$ and root uptake removes water from the soil with a composition $\alpha_{U} R_{\mathrm{S}}\left(\mathrm{s} . \mathrm{s}\right.$.) $=R_{\mathrm{P}}$. When the isotopic steady state is reached soil water will have an isotope ratio $R_{\mathrm{P}} / \alpha_{U}$ that is more enriched than irrigation water (by $3 \%$ in our example). During all this time, stem (xylem) water had the same isotope composition as root water uptake, i.e., $R_{\mathrm{x}}=\alpha_{\mathrm{U}} R_{\mathrm{s}}$, which is (over time) above or below $R_{\mathrm{P}}$ depending on the initial value of $R_{\mathrm{S}}$ compared to $R_{\mathrm{P}}$. However once isotopic steady state is reached, $R_{\mathrm{x}}$ reaches $R_{\mathrm{x}}$ (s.s.) $=\alpha_{\mathrm{U}} R_{\mathrm{S}}$ (s.s.) $=R_{\mathrm{P}}$, regardless of the initial value of $R_{s}$. In other words, at isotopic steady state, we should expect the isotope ratio of the stem (xylem) water to be the same as irrigation water, and soil water to be more enriched than 
irrigation water to an extent that reflects the isotope fractionation during root water uptake ? ? $_{\mathrm{U}}$. By no means, should we expect stem (xylem) water to become depleted in heavy isotopes compared to irrigation water.

The simple example above was derived assuming no soil evaporation. However, if soil evaporation is not completely suppressed, then this should create an isotopic enrichment of soil water different from the situation above and could also enrich stem (xylem) water. A mathematical treatment of this situation is therefore required. In the situation where water is removed from the soil by root uptake and soil evaporation, the soil water mass balance becomes:

$$
\frac{d W}{d t}=P \quad E \quad U \quad 0
$$

In this equation, $P, E$ and $U$ (in $L$ of water per day) represent the rates of irrigation, soil evaporation and root water uptake, respectively, $W$ is the soil water content (in L) and $t$ is time (in days). A similar mass balance equation can also be written for the heavy isotope species (either ${ }^{1} \mathrm{H}_{2}{ }^{18} \mathrm{O}$ or ${ }^{1} \mathrm{H}^{2} \mathrm{H}^{16} \mathrm{O}$ ):

$$
\frac{d W R_{\mathrm{S}}}{d t}=P R_{\mathrm{P}} \quad E R_{\mathrm{E}} \quad U R_{\mathrm{U}} \quad W \frac{d R_{\mathrm{S}}}{d t}
$$

In this equation, $R_{\mathrm{S}}, R_{\mathrm{P}}, R_{\mathrm{E}}$ and $R_{\mathrm{U}}$ are the isotope ratios of bulk soil water, irrigation water, soil evaporation and root water uptake, respectively. The second equality in Eq. S2 was obtained by decomposing the derivative of the product $W R_{\mathrm{S}}$ and noting that, according to Eq. $\mathrm{S} 1, \mathrm{~d} W / \mathrm{d} t=0$. In the following, we will express $R_{\mathrm{E}}$ and $R_{\mathrm{U}}$ with respect to $R_{\mathrm{S}}$ and introduce isotope fractionations: $R_{\mathrm{E}}=\alpha_{\mathrm{E}} R_{\mathrm{S}}$ and $R_{\mathrm{U}}=\alpha_{U} R_{\mathrm{S}}$. We will also express $E$ as a fraction of the root water uptake rate $U: E=f_{E} U$. (This notation does not imply any functional relationship between $E$ and $U$ but is there only to quantify the relative proportion of soil evaporation compared to root uptake). With this notation, Eq. S1 simplifies to $P=\left(1+f_{\mathrm{E}}\right) U$ and Eq. S2 can be re-arranged as:

$$
\frac{\mathrm{d} R_{\mathrm{s}}}{d t}+\frac{{ }_{\mathrm{U}} P}{W} \frac{1+{ }_{\mathrm{E}} /{ }_{\mathrm{U}} f_{\mathrm{E}}}{1+f_{\mathrm{E}}} R_{\mathrm{s}}=\frac{P}{W} R_{\mathrm{p}}
$$

At isotopic steady state, $\mathrm{d} R_{\mathrm{s}} / \mathrm{d} t=0$ and we obtain: 


$$
R_{\mathrm{s}}(\text { s.s. })=\frac{1+f_{\mathrm{E}}}{1+{ }_{\mathrm{E}} / \mathrm{u}_{\mathrm{U}} f_{\mathrm{E}}} \frac{R_{\mathrm{P}}}{\mathrm{U}}
$$

If $f_{\mathrm{E}}=0$ we have the situation described above where evaporation is totally suppressed and $R_{\mathrm{s}}($ s.s. $)=R_{\mathrm{P}} / \alpha_{\mathrm{U}}$. If $f_{\mathrm{E}} \neq 0$, then soil water will become even more enriched than $R_{\mathrm{P}} / ?_{\mathrm{U}}$ if $?_{\mathrm{E}} / ?_{\mathrm{U}}<1$ but it can also become less enriched if $\alpha_{E} / \alpha_{U}>1$. Note that, because both evaporation and root uptake are supposed to enrich soil water, $\alpha_{E}$ and $\alpha_{U}$ are both smaller than unity. Therefore, $\alpha_{E} / \alpha_{U}>1$ means that the isotopic enrichment of soil water caused by soil evaporation is smaller than the isotopic enrichment caused by root uptake. This is why the overall effect in this situation is to have a soil water pool that is less enriched than if root uptake was the only enriching process.

Equation S3 is also instructive because it gives an indication of the time constant required to reach isotopic equilibrium: $\tau \approx W / P$. With $P=0.06 \mathrm{~L} /$ day (this is coherent with our irrigation records and with Fig. S2b that shows that about $0.2 \mathrm{LL}^{-1}$ is lost in about 10 days at the beginning of the drought treatment for a total soil volume of about $3 \mathrm{~L}$ ) and $W=1.5 \mathrm{~L}$ (i.e. $3 \mathrm{~L}$ of soil with a water content of about $0.5 \mathrm{~L} \mathrm{~L}^{-1}$, see Fig. S2a), we obtain $\tau \approx 25$ days. This means that it takes about 1-2 months to reach isotopic steady state, approximately the duration of the irrigation period prior to our first sampling campaign (i.e. from February to mid-May 2018). Therefore, we should expect that isotopic steady state was attained by the time of our first sampling campaign.

Equation S4 has been derived by replacing $R_{\mathrm{E}}$ by $\alpha_{\mathrm{E}} R_{\mathrm{S}}$ but $\alpha_{\mathrm{E}}$ is not independent of $\alpha_{\mathrm{U}}$ and $f_{\mathrm{E}}$ (and all other variables affecting the isotopic composition of soil water at the evaporation site). Indeed, the isotope ratio of soil evaporation $\left(R_{\mathrm{E}}\right)$ is related to that of soil water at the evaporation site $\left(R_{\mathrm{es}}\right)$ and also to the isotope ratio of atmospheric vapour at the soil surface $\left(R_{\mathrm{v}}\right)$ (Barnes \& Allison, 1983; Farquhar et al., 2007):

$$
R_{\mathrm{E}}=\frac{R_{\mathrm{es}} / \mathrm{lv}_{\mathrm{v}} h R_{\mathrm{v}}}{(1 \quad h)_{\mathrm{k}}}
$$

where $h$ denotes air relative humidity at the soil surface and $\alpha_{l v}$ and $\alpha_{k}$ are the isotopic fractionations during liquid-vapour transition and water vapour diffusion from the evaporation 
site to the soil surface, respectively. $\alpha_{l_{v}}$ is only a function of soil temperature while $\alpha_{k}$ depends on the intensity of the airflow above the soil surface.

Because of isotope fractionations associated with soil evaporation and root uptake, the isotope ratio of soil water is not uniform, so that $R_{\mathrm{es}} \neq R_{\mathrm{s}}$, even if root water uptake is uniform throughout the soil profile. The isotope ratio of water vapour at the soil surface will also depend on the ratio of evaporation and transpiration $\left(f_{\mathrm{E}}\right)$, and water vapour exchange between the glasshouse atmosphere and the air underneath the plastic plate that covers the soil. If this exchange is slow we could assume that most of the water vapour at the soil surface comes from soil evaporation, so that $R_{\mathrm{v}}=R_{\mathrm{E}}$. In this situation, Eq. S5 can be re-arranged:

$$
R_{\mathrm{E}}=\frac{R_{\mathrm{es}}}{{ }_{\mathrm{lv}} h+(1 \quad h)_{\mathrm{lv}} \mathrm{k}}
$$

We can also define $Z\left(\alpha_{U}, f_{\mathrm{E}}\right)=R_{\mathrm{es}} / R_{\mathrm{S}}$ so that:

$$
\mathrm{E}=\frac{Z\left({ }_{\mathrm{u}}, f_{\mathrm{E}}\right)}{\mathrm{lv}_{\mathrm{v}} h+(1 \quad h)_{\mathrm{lv} \mathrm{k}}}
$$

To a good approximation, we can assume that in our control treatment, the soil column stays near saturation and we can neglect water vapour fluxes compared to liquid water fluxes. We also assume the soil column to be isothermal and root uptake to be uniform throughout the soil profile. In this situation, at steady state, the liquid water flux varies linearly with soil depth $(z)$ from $(P-E) /\left(A \rho_{\mathrm{w}}\right)=U /\left(A \rho_{\mathrm{w}}\right)=q_{10}$ at the soil surface $(z=0)$ to zero at the bottom $\left(z=z_{\max }\right)$ : $q_{l}=q_{10}\left(1-z / z_{\text {max }}\right)$. We normalised the fluxes $P, E$ and $U$ (in $\mathrm{L} /$ day or $\mathrm{kg} / \mathrm{s}$ ) by the soil area $(A)$ and water density $\left(\rho_{w}\right)$ to make sure that $q_{10}$ has the dimension of a velocity $(\mathrm{m} / \mathrm{s})$.

At isotopic steady state, the isotope ratio of soil water satisfies the following ordinary differential equation (see for example equation 11 of Haverd \& Cuntz, 2010):

$$
D_{1, \text { iso }} \frac{d^{2} R}{d z^{2}} \quad q_{10}\left(1 \quad z / z_{\max }\right) \frac{d R}{d z}+\frac{q_{10}}{z_{\max }}\left(\begin{array}{ll}
1 & \mathrm{u}
\end{array}\right) R=0
$$

The water isotope flux at the bottom of the soil column is zero (as for the total water flux $q_{1}$ ) and the flux at the soil surface is given by $q_{\mathrm{P}} R_{\mathrm{P}}-q_{\mathrm{E}} R_{\mathrm{E}}$ where $q_{\mathrm{P}}=P /\left(A \rho_{\mathrm{w}}\right)=q_{10}\left(1+f_{\mathrm{E}}\right)$ and $q_{\mathrm{E}}=E /\left(A \rho_{\mathrm{w}}\right)=q_{\mathrm{I}} f_{\mathrm{E}}$. 
Because $q_{1, \text { iso }}=q_{1} R-D_{1, \text { iso }}(\mathrm{d} R / \mathrm{d} z)$, these boundary conditions lead to:

$$
\left\{\begin{array}{l}
\left.\frac{d R}{d z}\right|_{z=z_{\max }}=0 \\
\left.q_{10} R(0) \quad D_{1, \text { iso }} \frac{d R}{d z}\right|_{z=0}=q_{\mathrm{P}} R_{\mathrm{P}} \quad q_{\mathrm{E}} R_{\mathrm{E}}
\end{array}\right.
$$

Defining $x=1-z / z_{\max }, P_{1}=q_{10} z_{\max } / D_{1, \text { iso, }}$ and $y(x)=R(z)$, Eq. S8 can be re-arranged:

$$
\frac{d^{2} y}{d x^{2}}+P_{1} x \frac{d y}{d x}+P_{1}(1 \quad \text { u }) y=0
$$

Making use of Eq. S6 and noting that $R_{\mathrm{es}}=R(0)=y(1)$, the boundary conditions (Eq. S9) become, with these new notations:

$$
\left\{\begin{array}{l}
\left.\frac{d y}{d x}\right|_{x=0}=0 \\
\left.\frac{1}{P_{1}} \frac{d y}{d x}\right|_{x=1}+\left[1+f_{\mathrm{E}} \frac{1}{{ }_{\text {lv }} h+\left(\begin{array}{lllll}
1 & h)_{\text {lv }} & \mathrm{k}
\end{array}\right] y(1)=\left(1+f_{\mathrm{E}}\right) R_{\mathrm{P}}}\right.
\end{array}\right.
$$

A solution of Eq. S10 with the boundary condition at $x=0$ is provided by Farquhar and Gan (2003) and is a confluent hypergeometric series of the first kind, or Kummer function ${ }_{1} F_{1}(a, b$, $x):$

$$
y(x)=a_{0} \cdot{ }_{1} F_{1}\left(\frac{1}{2}, \frac{1}{2}, \frac{P_{1}}{2} x^{2}\right)
$$

The constant $a_{0}$ is obtained using the second boundary condition, knowing that:

$$
\frac{d}{d x}\left\{{ }_{1} F_{1}\left(a, b, 0.5 P_{1} x^{2}\right)\right\}=\frac{a}{b} P_{1} \times\left\{{ }_{1} F_{1}\left(a+1, b+1,0.5 P_{1} x^{2}\right)\right\}
$$

This gives:

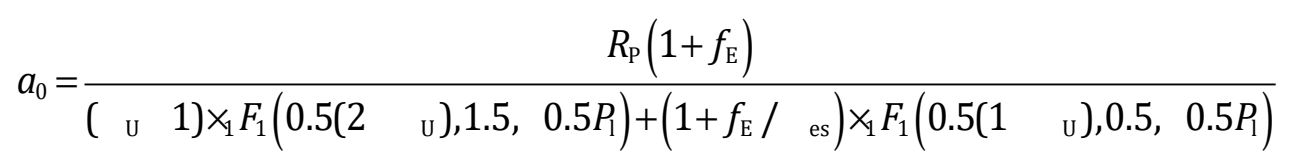

where $\alpha_{\mathrm{es}}=\alpha_{\mathrm{Iv}} h+(1-h) \alpha_{\mathrm{lw}} \alpha_{\mathrm{k}}$. From Eqs. S12 and S14 we can compute $R_{\mathrm{es}}=R(0)=y(1)$ for any values of $\alpha_{U}$ and $f_{\mathrm{E}}$. 
Integrating Eq. S10 between 0 and 1 also gives:

$$
R_{\mathrm{s}}=\int_{0}^{1} y d x=\frac{1}{\mathrm{U}}\left[R_{\mathrm{P}}\left(1+f_{\mathrm{E}}\right) \quad R_{\mathrm{es}} \frac{f_{\mathrm{E}}}{\mathrm{es}}\right]
$$

We will note that Eq. S15 is simply a re-arrangement of Eq. S4 where $\alpha_{\mathrm{E}}=R_{\mathrm{E}} / R_{\mathrm{S}}$ has been replaced by $\left(R_{\mathrm{es}} / \alpha_{\mathrm{es}}\right) / R_{\mathrm{s}}$. From Eq. S15 we can compute $\mathrm{Z}\left(\alpha_{\mathrm{U}}, f_{\mathrm{E}}\right)=R_{\mathrm{es}} / R_{\mathrm{S}}$ and finally $\alpha_{\mathrm{E}}$, but this extra step is a bit unnecessary if we are only interested in $R_{\mathrm{s}}, R_{\mathrm{es}}$ and eventually $R_{\mathrm{x}}=R_{\mathrm{U}}=\alpha_{\mathrm{U}} R_{\mathrm{s}}$ because all these quantities can be computed from Eqs. (S12-S15).

Steady-state values of $R_{\mathrm{S}}, R_{\mathrm{x}}$ and $R_{\mathrm{es}}$ are shown in Fig. S9 as a function of $f_{\mathrm{E}}$ and for different values of $\varepsilon_{U}=\alpha_{U}-1$. We assumed a soil surface area of $10 \mathrm{~cm}^{2}$ (leading to $q_{\mathrm{P}} \approx 70 \mu \mathrm{m} / \mathrm{s}$ ), a maximum soil depth of $35 \mathrm{~cm}$ (leading to a soil volume of $3.5 \mathrm{~L}$ ) and air temperature and relative humidity of $27^{\circ} \mathrm{C}$ and $70 \%$, respectively. We also indicated the range of values for $R_{\mathrm{s}}$ and $R_{\mathrm{x}}$ that we observed in our control experiment (see Fig. 3 in the main text).

First, we can see that when $f_{\mathrm{E}}=0, R_{\mathrm{x}}=R_{\mathrm{p}}$ and $R_{\mathrm{S}}=R_{\mathrm{p}} / \alpha_{\mathrm{U}}$, as already predicted by Eq. S4, and also $R_{\mathrm{es}}=R_{\mathrm{s}}$. When $f_{\mathrm{E}}>0 \quad R_{\mathrm{x}}$ becomes slightly more enriched than $R_{\mathrm{p}}$, but increasing fractionation during root uptake (i.e. taking more negative $\varepsilon_{\cup}$ values) does not affect $R_{\mathrm{x}}$ but only enriches $R_{\mathrm{S}}$ above $R_{\mathrm{x}}$ by about $-\varepsilon_{\mathrm{U}}$. For $f_{\mathrm{E}} \approx 0.05-0.1$ and $\alpha_{\mathrm{U}}=1$, our predictions for $R_{\mathrm{S}}$ match well the observations for both ${ }^{2} \mathrm{H} /{ }^{1} \mathrm{H}$ and ${ }^{18} \mathrm{O} /{ }^{16} \mathrm{O}$ ratios, supporting the idea that no fractionation during root water uptake occurred. Our predictions for $R_{\mathrm{x}}$ at $f_{\mathrm{E}} \approx 0.05-0.1$ also match well our observations, but only for oxygen isotopes. For hydrogen isotopes, our observations of bulk stem (xylem) water cannot be explained by any combination of $f_{\mathrm{E}}$ and $\alpha_{\mathrm{U}}$. We conclude from this analysis that, if soil evaporation was probably not completely suppressed in our control treatment $\left(f_{\mathrm{E}} \approx 0.05-0.1\right)$, fractionation during root water uptake does not seem to have occurred $\left(\alpha_{U}=1\right)$ thus another fractionation process must be responsible for the observed depletion of bulk stem water compared to soil water in the control treatment. Isotopic heterogeneity between vessel water (with isotope ratio $\alpha_{U} R_{\mathrm{s}}=R_{\mathrm{s}}$ ) and other xylem tissues could explain such depletion if xylem tissues were depleted compared to vessel water. 
Figure S9. Isotope ratios $R_{\mathrm{es}}, R_{\mathrm{s}}$ and $R_{\mathrm{x}}$, expressed as enrichment above irrigation water $R_{\mathrm{p}}$, and computed using Eqs. S13 and S15 for different values of $f_{\mathrm{E}}$ and $\alpha_{\mathrm{U}}$. Observed ranges are also indicated.

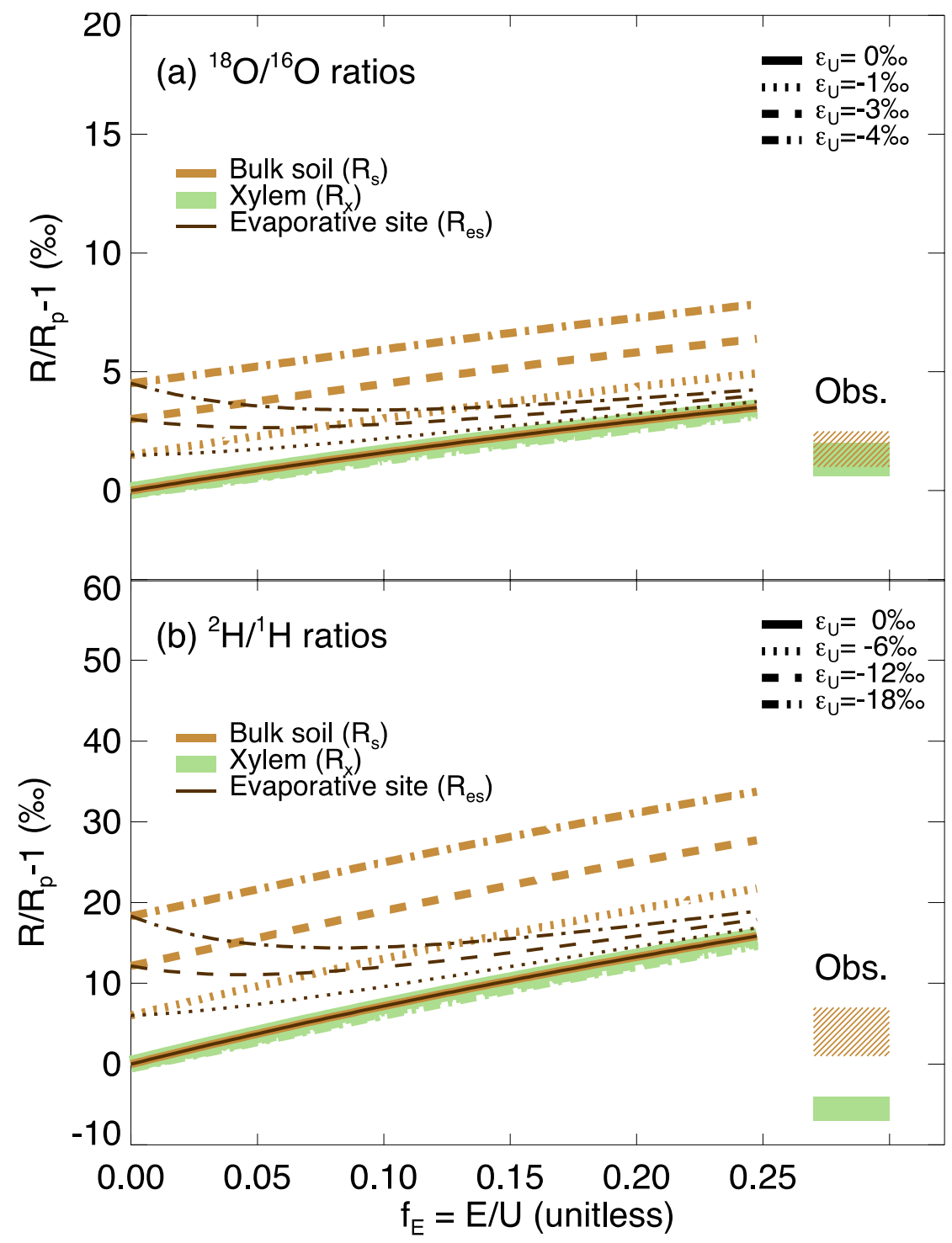


Figure S10. Boxplots of the soil gravimetric water content (GWC, a and b), predawn leaf water potential $\left(\Psi_{\mathrm{pd}}, \mathrm{c}\right.$ and $\left.\mathrm{d}\right)$, plant water content (e and f) and stomatal conductance ( $g$ and $h$ ) in control ( $a, c, e$ and $g$ ) and drought-stressed pots (b, $d, f$ and $h$ ). Boxplots show the interquartile range, the median (black line), the minimum and the maximum values (whiskers) besides outliers (black dots), with $\mathrm{N}=10$ and 5, for GWC and plant water content, and $\mathrm{N}=5$ and 3 for $\Psi_{\text {pd }}$ and stomatal conductance, for drought and control, respectively. 


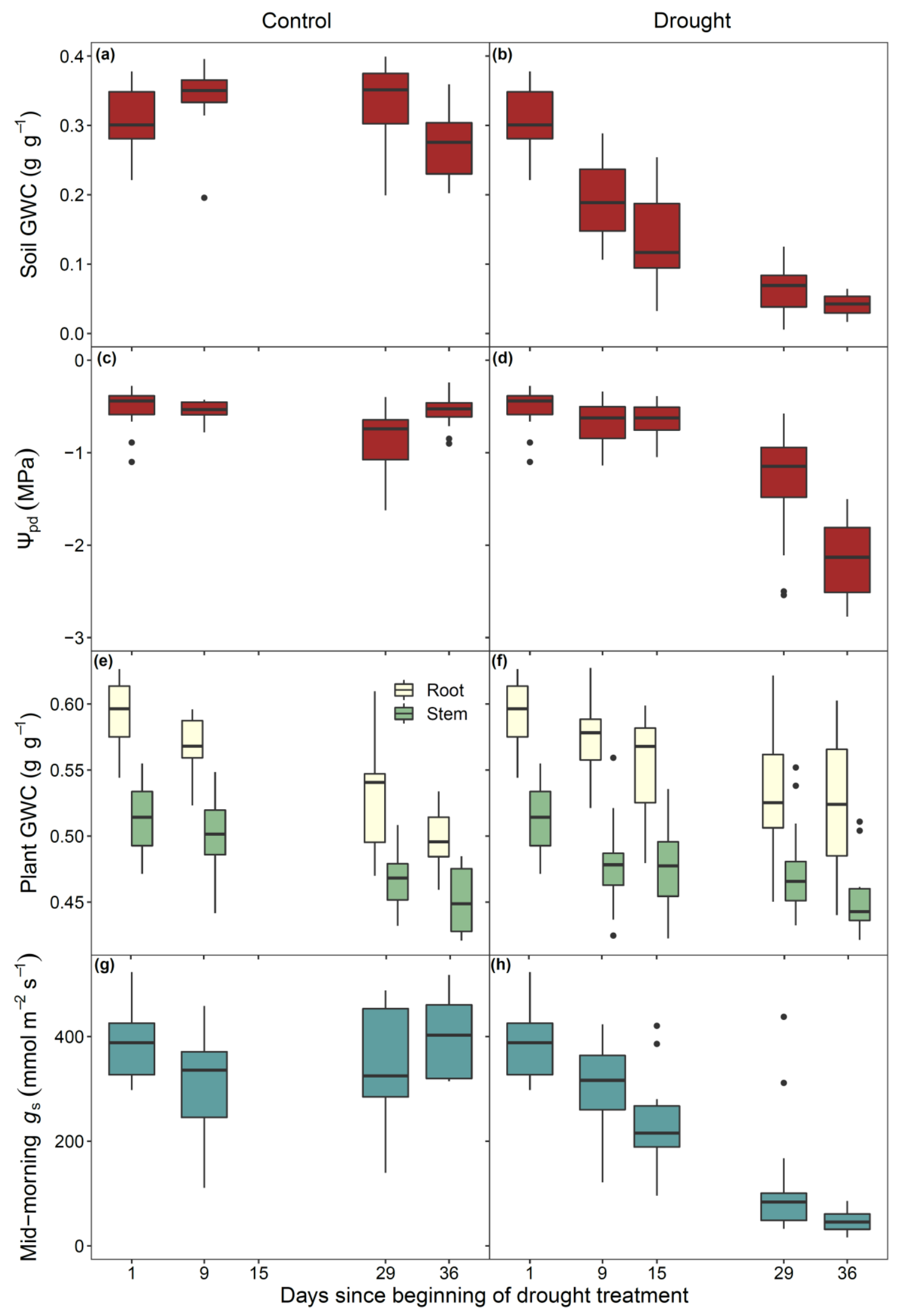


Figure S11. Boxplots of the isotopic composition of soil, root and stem water in control $(a, c)$ and drought-stressed pots (b, d). Boxplots show the interquartile range, the median (black line), the minimum and the maximum values (whiskers) besides outliers (black dots), with $\mathrm{N}=15$ and 9 for drought and control, respectively.

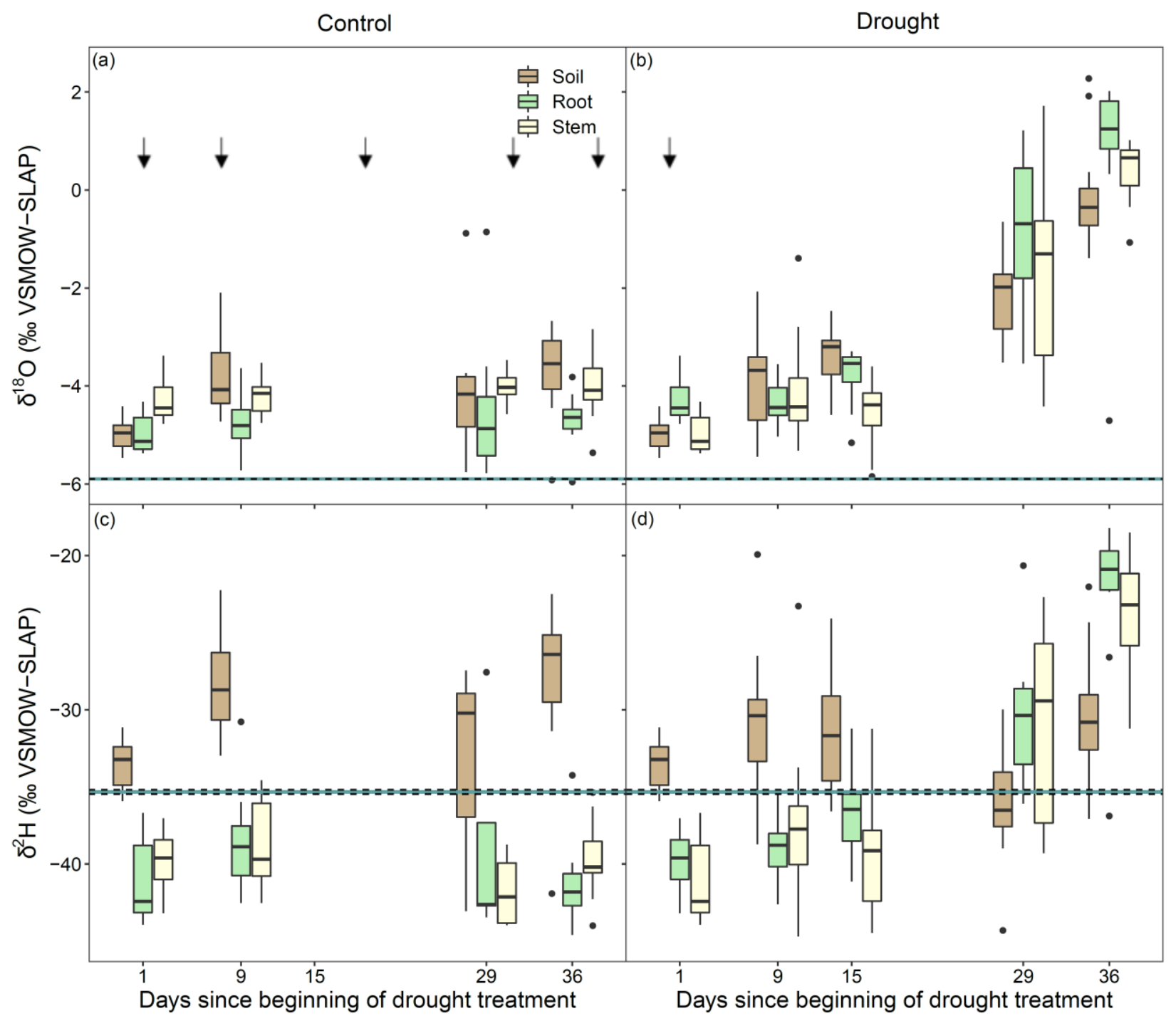

\section{References}

Barnes C, Allison GB. 1983. The distribution of deuterium and ${ }^{18} \mathrm{O}$ in dry soils .1. Theory. Journal of Hydrology 60: 141-156.

Farquhar GD, Gan K. 2003. On the progressive enrichment of the oxygen isotopic composition 
of water along a leaf. Plant Cell and Environment 26: 801-819.

Farquhar GD, Cernusak LA, Barnes B. 2007. Heavy Water Fractionation during Transpiration. Plant Physiology 143: 11-18.

Haverd V, Cuntz M. 2010. Soil-Litter-Iso: A one-dimensional model for coupled transport of heat, water and stable isotopes in soil with a litter layer and root extraction. Journal of Hydrology 388: 438-455. 